\title{
Una necesaria revisión de las cerámicas andalusíes halladas en Italia
}

\author{
Rafael Azuar*
}

\begin{abstract}
RESUMEN
Transcurridos más de veinte años desde la publicación de la monumental investigación sobre los "bacini" de las iglesias de Pisa y más de cinco desde que la profesora G. Berti publicara su última revisión y actualización sobre las importaciones andalusíes. Es necesaria una revisión de los diversos centros de producción de las cerámicas provenientes de al-Andalus y de sus cronologías.
\end{abstract}

PALABRAS CLAVE: Al-andalus, cerámicas, alfares, exportacion, Italia, mediterráneo.

La monumental investigación llevada a cabo por Graziella Berti y Liana Tongiorgi sobre los bacini que decoraban las iglesias de Pisa (I98I), permitió elaborar una primera información sobre las importaciones cerámicas andalusíes de los siglos $X$ al $X V$ halladas en las iglesias de Pisa, que se presentó, ese mismo año, en el II Coloquio de Cerámica Medieval del Mediterráneo Occidental celebrado en Toledo (BERTI, TONGIORGI, 1986). Aquel encuentro sirvió para organizar una importantísima investigación en colaboración con Guillermo Rosselló que permitió documentar en Mallorca la existencia de un taller de cerámicas decoradas en "verde y manganeso", de fines del siglo $X$ y principios del siglo XI (BERTI, ROSSELLÓ, TONGIORGI, 1986).

* MARQ (Museo Arqueológico Provincial de Alicante).

\begin{abstract}
More than twenty years have passed since the publication of the important investigation on the "bacini" of the churches of Pisa and more than five years since Professor G. Berti published her latest review and update on Andalusi imports. Therefore a review of the different centres of production of Al-Andalus pottery and their chronologies is necessary.
\end{abstract}

KEY WORDS: Al-Andalus, pottery, potter's workshop, export, Italy, Mediterranean.

Aquellas primeras investigaciones fueron ampliándose con estudios mineralógicos desarrollados en colaboración con el profesor Tiziano Mannoni, lo que les permitió no sólo confirmar la existencia del taller mallorquí, sino también identificar otros centros alfareros andalusíes dedicados a la producción de cerámicas en "cuerda seca total" o a la tan mencionada "loza dorada" de al-Andalus (BERTI, MANNONI, 1995).

Gracias a estos estudios desarrollados por nuestros colegas investigadores italianos y cuya última síntesis fue presentada por la misma Graziela Berti en el XXXI Convenio Internacional de la Cerámica de Albisola (1997-8) y en el I Congreso Nacinal de Arqueología Medieval de 
Italia, celebrado en Pisa en el año 1997 (BERTI, 2000), - un avance de estas conclusiones ya había sido presentada por la misma G. Berti, en colaboración con Sauro Gellici, en el congreso Medieval Europe 92 celebrado en York (Inglaterra), cuyo texto fue publicado en nuestro Boletin de Arqueología Medieval (BERTI, GELLICl, 1992)-, hoy, en el ámbito mediterráneo, se habla de determinadas producciones cerámicas andalusíes de exportación que se han hallado en Italia y que, paradójicamente, todavía no se han localizado sus centros de producción en la península ibérica.

Sobre esta cuestión y sobre la difícilmente explicable alta cronología de las cerámicas andalusíes halladas en Italia, de tal manera que determinadas producciones poseen una cronología deposicional un siglo anterior a la de su origen en al-Andalus, ya me pronuncié en mi estudio que realicé sobre "Al-Andalus y el comercio mediterráneo del siglo XI, según la dispersión y distribución de las producciones cerámicas" (AZUAR, 1998). Recientemente, he tenido ocasión de volver sobre este tema en una investigación más amplia presentada en el IV Seminario internacional ANSER, sobre Rotte e porti del mediterraneo dopo la caduta dell'Impero romano d'occidente, celebrado en el mes de Junio de este año 2004 en Génova y que trataba de las "Rutas y comercio de al-Andalus con las repúblicas italianas de Génova, Pisa y Amalfi, de los siglos XI al XIII", en la que revisé las diversas producciones y los talleres identificados no sólo en los ricos conjuntos de bacini que decoran las iglesias italianas, sino también en las cerámicas halladas en el transcurso de los últimos veinte años de excavaciones en Italia, cuya geografía de aparición y dispersión ha sido motivo de varios estudios de Alberto Garcia Porras (1999-2000; 2003) Esta investigación es la base de la información que presentamos, con el objetivo de que sirva de interés y motivo de reflexión para los investigadores de las cerámicas y sus centros de producción en al-Andalus, con el fin de aunar criterios encaminados a ratificar o refutar las hipótesis asumidas en la investigación internacional sobre las producciones cerámicas de al-Andalus, su cronología y su dinámica en el Mediterráneo.

\section{LA PRODUCCIÓN CERÁMICA EN "VERDE Y MANGANESO I MORADO” DE MALLORCA}

La identificación de ejemplares con decoración en "verde y morado" entre los ricos conjuntos de bacini ya fue dada a conocer por G. Berti y L. Tongiorgi (198I). La presentación de estos hallazgos en el coloquio internacional celebrado en Toledo (BERTI, TONGIORGI, 1986), supuso el inicio de una serie de investigaciones posteriores y específicas sobre esta producción, en colaboración con Guillermo Rosselló (1986) y con el profesor Tiziano Mannoni, que realizó exhaustivos análisis metalográficos de sus pastas y vidriados (BERTI, MANNONI, 1991, 1997); de tal manera que les llevó a la clara identificación de un grupo de cerámicas procedentes de un centro productor de Mallorca, con una clara cronología del último cuarto del siglo X y primer cuarto del siglo XI (BERTI, ROSSELLÓ, TONGIORGI, 1986).

Los bacini procedentes de Mallorca, según los análisis de sus pastas, serían los números I I (BERTI, TONGIORGI, 1981, tv. Cll, 193), I8, 19, 53, 59 y 62 (BERTI, TONGIORGI, 1981, tv, CII, Cl, C, IC, XCVIII, fg.86, 19I-2), todos ellos hallados en la iglesia de San Piero a Grado y con el mismo y característico perfil carenado con una pequeña moldura en el labio de su borde superior, excepto el caso del ejemplar $n^{\circ}$ II que es de perfil curvo, sin carena y de tamaño mucho más reducido. Todos ellos fueron objeto de un estudio específico y comparativo con los ataifores hallados en Mallorca, realizado en colaboración con G. Rosselló Bordoy (BERTI, ROSSELLÓ, TONGIORGI, 1986) en el que se analizaban decorativamente los $n$. 19 y 59 (Fig. I) que portan, como algo excepcional, la representación de unas naves, cuyos rasgos coinciden con la descripción que el poeta dianense Ibn al-Labbâna efectuó, a principios del siglo XII, de la parada naval que se desarrolló en la bahía de Palma, con motivo de celebrar el solsticio de verano (ROSSELLÓ, 1993).

En el mismo conjunto de ataifores procedentes de Mallorca, se encuentra el número 
53 (BERTI, TONGIORGI, 1981, tv. XCVIII, fg. 86) con una decoración fitomorfa formada por una organización geométrico-estrellada cuyos tallos terminan en ocho piñas u hojas (Fg. 2). De similar decoración, aunque de cuatro hojas, y forma es un ataifor aparecido en las excavaciones de Santa Catalina de Sena de MaIlorca (ROSSELLÓ, 1978, I1 0, fg.56) que fue estudiado conjuntamente (BERTI, ROSSELLÓ, TONGIORGI, 1986) y que, sin embargo, en la exposición de Marsella del año 1996, G. Rosselló retomó su consideración primera, catalogándolo como un ataifor de época Taifa, con una datación de los siglos XI-XII (ROSSELLÓ, 1996, I I 0, n.85).

\section{LA PRODUCCIÓN EN "VERDE Y MANGANESO” DE MÁLAGA?}

De entre el grupo de bacini decorados en "verde y manganeso" y considerados como andalusíes no procedentes de Mallorca (BERTI, TONGIORGI, (98I), los análisis metalográficos efectuados recientemente por G. Berti y T. Mannoni $(1997,435)$ les ha permitido aislar e identificar una reducida serie de ataifores con un posible centro de producción en el área de Málaga.

Entre ellos, el más importante sería el bacini n. 2, procedente de San Zeno (BERTI, TONGIORGI, 198I, tv. LVI, fg. 50, 167) que presenta evidentes diferencias formales con los hallados en la iglesia de S. Piero a Grado, procedentes de Mallorca. Es decir, este ataifor es de paredes abiertas ligeramente curvas, con borde exvasado y en su base presenta un pie anular, levemente marcado, distinto a los pies desarrollados de los ejemplares mallorquines. Si su forma es totalmente diferente, lo es más su decoración y tratamiento, ya que presenta como motivo una escena de zoomorfos de carácter simbólica, inusual en los ejemplares de Mallorca, en la que aparece un pavón en posición invertida sobre un león andante. Las figuras poseen un tratamiento muy estilizado, rematándose el conjunto con una decoración de ovas en su borde (Fg. 9.I).
Sus rasgos tipológicos y decorativos lo separan evidentemente del conjunto mallorquí. Por contra, posee muchas similitudes, formales y decorativas, con el ataifor hallado en las excavaciones de la alcazaba de Mértola $n$. CR/VM/000I (Fg. 9.2), que fue dado a conocer por Claudio Torres en la exposición de Lisboa (TORRES, 1987) y estudiado posteriormente por Susana Gómez, considerándolo en aquel momento como de origen Kairauaní (Túnez) (1994, fg. 55, 124), aunque, con motivo de la exposición "Portugal Islâmico" organizada en Lisboa en el año 1998, se replanteó este origen, admitiendo la posibilidad de que proceda de al-Andalus y con una cronología de la segunda mitad del siglo XI (1998, n.62, 100), siguiendo las conclusiones de los análisis efectuados por G. Berti y T. Mannoni (1997)

El debate sobre el origen de esta producción no se ha cerrado, tras el descubrimiento de los hornos califales-taifales de Dénia, su descubridor Josep A. Gisbert llegó a sugerir que estas cerámicas en "verde y manganeso", junto con los ataifores decorados con escenas de barcos, considerados como mallorquines como se ha visto, podrían proceder de los alfares califales de Dénia (GISBERT, 2003, 75-6). La cuestión entre los investigadores españoles está totalmente abierta y sin los necesarios estudios que clarifiquen si estos singulares ataifores proceden de desconocidos alfares malagueños o dianenses, o por el contrario proceden de algún centro alfarero del norte de Africa. Para los investigadores italianos, no ofrece lugar a dudas la producción malagueña de los mismos, con la salvedad de que G. Berti considera al ejemplar pisano como del primer cuarto del siglo XI (BERTI, 1997-8, 243), mientras que el ejemplar de Mértola, arqueológicamente, está fechado hacia la segunda mitad del siglo.

\section{III.DEL INCIERTO ORIGEN DE LOS BACINI EN “CUERDA SECA TOTAL"}

El estudio de las cerámicas que decoran las iglesias de Pisa permitió la identificación de 
varios ejemplares realizados con la técnica de la "cuerda seca total" ' y que son los siguientes: dos ataifores en la fachada de las iglesias Pisanas de San Piero a Grado (nn. 31 y 63) y uno en la de San Zeno (n. 6) (BERTI, TONGIORGI, 198I, 163-5, tav. LII yLIV); otro ejemplar en la iglesia de San Sisto de Lucca (n, I54 ) (BERTI, TONGIORGI, 198I, 163-5, tav. LIII). En sus investigaciones hacen mención de otro documentado en San Nicolás de Chiastra (Córcega). A esta conocida y reducida lista de piezas hay que añadir un pequeño fragmento (PSC 3078-9) aparecido en el transcurso de las recientes excavaciones realizadas en la Plaza de Santa Caterina de Finalborgo (Savona) (FRONDONI, MURIALDO, PALAZZI, PANIZZA, PARODI, 1999-2000), que fue estudiado por A. García Porras el cual nos dice que se encontró en un nivel cronológico de la segunda mitad del siglo XIII (GARCIA, 2003, 243, Tav. I.I) y que por su reducido tamaño apenas se puede decir algo más del mismo.

De los hallados en San Piero a Grado, el ejemplar más completo es el número 63 (Fg. 3. I) Es un ataifor de perfil quebrado y que presenta como rasgo tipológico diferenciador, indiscutiblemente, su marcado borde en ala. En su base posee un repie anular. Se decora al interior con una red de rombos realizados en color verde, con rombos inscritos en color melado con gotas de esmalte verde en su centro que contrastan con el color blanco del fondo (BERTI, TONGIORGI, 1981, fg. 48, 164). Su característico perfil quebrado podría emparentarse, como ya avanzaran G. Berti y T. Mannoni (1995, 40I), con el tipo 2 de la colección procedente de la alcazaba de Málaga y en concreto con el ejemplar B-7 (PUERTAS, 1989, fg. 16, 12).

En esta misma colección de la alcazaba de Málaga, encontramos cuatro ataifores (PUERTAS,
1989, n B-8, 28, 41, 80, fg. 18, 20, 21,22; BERTI, MANNONI, 1995, 40I) de forma y decoración similar al n. 31, hallado en la misma iglesia de San Piero a Grado (BERTI, TONGIORGI, I98I, fg. 47, 164, LIV.2), del que también se conocen ejemplares en Mallorca (ROSSELLÓ, 1978, fg. 62, pp. 116) y en la alcazaba de Mértola (Portugal) (Fg. 3.2) (TORRES, GÓMEZ, 1996, fg. 82, 102) Todos ellos con una amplia cronología de los siglos XI y XII, que en el caso del ejemplar portugués en este momento se le considera como propio del siglo XII (GÓMEZ, 2002, N. 37, 129; GÓMEZ, DELERY, 2002).

De San Sisto procede el $n^{\circ}$ |54, de perfil similar al $n^{\circ} 31$, pero con una decoración totalmente diferente, de motivos vegetales dividiendo el fondo el ataifor en cuatro espacios iguales. Esta ordenación decorativa no la hemos encontrado en las cerámicas de "cuerda seca" aunque claramente está inspirada en las decoraciones de la cerámica "verde y manganeso", como así se aprecia en los registros de Madinat al-Zahrâ (CANO, 1996), o las producciones del alfar de San Nicolás de Murcia (NAVARRO, 1990, fg.6-17), por citar algunos ejemplos.

El ejemplar hallado en Lucca presenta una decoración geométrica con motivos vegetales que, aunque no hemos hallado un ejemplar similar, el trazo y el diseño decorativo sugiere una evidente afinidad con las cerámicas a "cuerda seca" malagueñas, sobre todo en el tratamiento de las "piñas" en los ataifores del tipo 3 , aunque su perfil con borde moldurado no aparece en su registro formal (PUERTAS, 1989).

Los paralelos formales y decorativos de estos bacini son, hasta el momento, muy escasos; apenas se identifican con claridad los de la iglesia de San Piero a Grado (Pisa), exceptuando el ejemplar número 3I, con claros para-

\footnotetext{
Es una técnica decorativa de la cerámica andalusí, de la que se efectuó un primer intento de identificación de sus orígenes a cargo de M. Casamar y F. Valdés (1984) y a la que definitivamente se la considera como una producción propiamente de al-Andalus (RETUERCE, ZOZAYA, 1986). Su producción está documentada en distintos centros alfareros, como serían Toledo (AGUADO, 1983, 1990) o Badajoz (VALDÉS, 1985), aunque por la distribución y concentración de su aparición en la península ibérica no sería extraña la existencia de otros centros en el área de la desembocadura del Gudalquivir, entre Sevilla y el Algarbe (TORRES, 1987), en el área de Málaga (PUERTAS TRICAS, 1989) o en el mismo centro de la ciudad de Valencia ( SOLER FERRER, I990), sin olvidar su posible procedencia de los alfares de la ciudad de Murcia, en atención a los análisis de sus pastas (BERTI, MANNONI, I995) y al alfar de Almería, en donde se ha constatado su presencia (FLORES et alii, 1999).
} 
lelos en la península y de una amplia geografía de aparición: en Málaga, Mallorca y en Mértola, así como de una cronología imprecisa entre los siglos Xl y XIl. Sin embargo, las dataciones que nos aportan los edificios de donde proceden en Italia nos sitúan ante un horizonte cronológico diferente y muy anterior (BERTI, GELI$\mathrm{CHI}$, 1992). Así, según afirma la profesora G. Berti los números 6, 31 y 63, precisamente los de esta iglesia de San Piero a Grado, fueron colocados entre el último decenio del siglo $X$ y los primeros años del siglo XI (BERTI, TONGIORGI, 198I, 153-7; BERTI, MANNONI, 1995, 400; BERTI, 1997-8, 244).

Cronología que, como ya expuse en otra ocasión (AZUAR, 1998, 57), es imposible para estas cerámicas con esta técnica decorativa, pues sus contextos arqueológicos de aparición en los yacimientos de la península ibérica son siempre posteriores al siglo $X$, -en contra de la opinión de C. Delery (2003)-, y en el caso del Sharq al-Andalus o en el levante, se limita exclusivamente a su segunda mitad (AZUAR, 1989, 324-327), al igual que sucede en la meseta interior de la península (RETUERCE, 1998, 4156). Más aún, la técnica continuará desarrollándose en los siglos XII y XIII, como atestiguan las excavaciones, como son los casos de los conjuntos hallados en las alcazabas de Mértola (TORRES, GÓMEZ, 1996; GÓMEZ, DELERY, 2002) O en la alcazaba de Málaga (PUERTAS, 1989), aspecto éste que ya demostré al estudiar los conjuntos procedentes de Denia (AZUAR, 1989, 324327), en donde se constata la presencia de cerámicas decoradas a la "cuerda seca" entre los materiales aparecidos en sus alfares de época almohade (GISBERT, AZUAR, BURGUERA, 199 I; GISBERT, GURGUERA, BOLUFER, 1992).

Otro dato importante que confirma la cronología de esta producción como del siglo XI pleno es que esta técnica, hasta el momento, no se ha documentado en ninguno de los alfares conocidos y estudiados de época califal en los que se fabricaban las cerámicas en "verde y manganeso". Así, no se ha documentado en los niveles califal-Taifal de los alfares de Denia hallados en la calle Ramón Ortega (GISBERT, 2000); ni en los complejos alfareros murcianos de C/ Ceferino, Cortés y Pedro de la Flor
(MUÑOZ, 1996, 25-28) en cuyo estudio se hace mención específica de la ausencia de esta técnica decorativa (MUÑOZ, 1993, 183); ni en los alfares de Pechina (Almeria) de pleno siglo $X$ (ACIÉN, 1990; 1996, 21-2); ni en los alfares del circo de Toledo (MARTINEZ, 1990), así como tampoco se ha documentado en los alfares califales de Zaragoza (MOSTALAC, 1990). Hasta el día de hoy, en ninguno de los centros alfareros de época califal de los siglos $X$ y principios del siglo $\mathrm{Xl}$, publicados, se ha podido documentar la presencia de esta producción tan específica como es la técnica de la "cuerda seca ". Por todo ello, resulta muy problemática la adscripción cronológica defendida por la profesora G. Berti para el conjunto italiano (1997-8), a no ser que los mismos no se hubieran producido en al-Andalus; aunque, según el estudio realizado junto con el profesor T. Mannoni (1995), parece ser que los bacini n. 63 de San Piero a Grado y el n. 154 de de la iglesia de S. Zeno (Pisa), mineralógicamente son similares entre ellos e idénticos a la composición de pasta de un ataifor de loza dorada procedente de alfares de Murcia (BERTI, MANNONI, 1995, 403; BERTI, 1997-8, 244). Es decir, no hay lugar a dudas sobre que los mismos procedan de al-Andalus, aunque curiosamente la cronología del ataifor de referencia, con la técnica de la "loza dorada", sea del siglo XII.

\section{LOZA DORADA PROCEDENTE DE LOS ALFARES DE AL-ANDALUS}

A finales de los años setenta, los análisis químicos realizados en Francia permitieron a G. Berti y L. Tongiorgi establecer que la mayoría de las lozas doradas halladas en Italia procedían o habían sido fabricadas en la península ibérica (1980, 84-85). Tras la publicación de los bacini de Pisa se identificaron casi una treintena de piezas de "loza dorada" como procedentes de al-Andalus y perfectamente enmarcables 0 encuadrables en el siglo XII (BERTI, TONGIORGI, 1981, 262-268). Escasos años después se produjo el extraordinario hallazgo en las excavaciones efectuadas en un solar de la calle Serrano Alcázar, junto a la muralla islámica de la ciudad de Murcia, de un ataifor en loza dorada, con 
una decoración vegetal de cuatro piñas en su centro, muy similar en forma y decoración a alguno de los bacini de las iglesias de Pisa. Este hallazgo fue presentado por Julio Navarro en el congreso de Siena de 1984 (NAVARRO, 1986), en donde también dio a conocer el resultado de los análisis metalográficos realizados por $\mathrm{M}$. Picón, sobre 10 fragmentos de loza dorada, dos hallados en la ciudad de Murcia y el resto encontrados en el cerro del castillo de Cieza, lo que les permitió confirmar que todas las lozas doradas eran producciones locales, realizadas en algún alfar de Murcia (PICÓN, NAVARRO, 1986), ratificando arqueológicamente la información documental del geógrafo musulmán Ibn Sa'id el Magribí (1213-1286), quién afirmaba: "se fabrica en Murcia, Málaga y Almería un vidrio de calidad y una cerámica vidriado dorada" (MARTINEZ CAVIRÓ, 1995, 149).

Aquellos primeros resultados fueron confirmados con el análisis metalográfico efectuado años después por T. Mannoni el cual, gracias a la comparación de los resultados del análisis del ejemplar de loza dorada de Murcia con el efectuado a las cerámicas decoradas a "cuerda seca" de Pisa, pudo confirmar que tenían una procedencia también murciana (BERTI, MANNONI, 1995, 403). De este, todavía no identificado alfar murciano, podría provenir el ejemplar de ataifor de Zavellá (Palma de Mallorca), estudiado por el propio J. Navarro y de una cronología del primer cuarto del siglo XIII, aunque opinaba que podría datarse en la segunda mitad del siglo XII (NAVARRO, 1987, 229).

Ciertamente, el ataifor murciano se caracteriza por su perfil quebrado y borde en ala. Forma y tipo éste que, como afirmaron G. Berti y L. Tongiorgi, sólo corresponden al n. I65, procedente de la iglesia de S. Sisto (I98I, fg. 222, 262), ya que todos los demás poseen un mismo perfil de paredes curvas, que les da la apariencia de ataifores de casquete esférico (BERTI, TONGIORGI, 1981, 262-6). De paredes curvas y decoración muy parecida al n. 364 (BERTI, TONGIORGI, 1981, fg. 229, tv. CCII, 268) es el ataifor hallado en la Cova dels Amagatalls de Mallorca con una inscripción en cursiva nesjí y con la típica forma de cuenco abierto, característico de los ataifores hallados en esta cueva, con una cronología del primer cuarto del siglo XIII, coincidiendo con la cronología de los bacini italianOs (BERTI, TONGIORGI, 1981, 230; BERTI, 1997-8, 246) (Fg. 4).

La definición de este grupo como procedente de al-Andalus (BERTI, 1987-8) abre grandes expectativas para la investigación en la península, ya que hasta el momento no se ha avanzado nada respecto a las investigaciones que desarrollara J. Navarro en la década de los ochenta y que permitieron identificar la producción murciana de "loza dorada", caracterizada por ataifores de perfil quebrado, de las que se desconoce su alfar o centro de producción, con una cronología que nuevamente es medio siglo posterior a la datación de los ejemplares hallados en Italia, quedando por aclarar, entre otras cuestiones, si los ataifores de perfil curvo, los más abundantes en Pisa, proceden de centros de producción andalusíes.

\section{BACINI CON DECORACIÓN ESTAMPILLADA BAJO CUBIERTA VIDRIADA DE COLOR VERDE}

Ampliamente tratada e identificada esta producción por $\mathrm{G}$. Berti en su reciente revisión de las cerámicas andalusíes halladas en Pisa (BERTI, 1997-8, 245), gracias a la cual sabemos que conforma uno de los lotes cuantitativamente más importantes de piezas andalusíes halladas en Italia, que asciende a la cifra de 17 bacini o ataifores. El más antiguo, fechado en el segundo cuarto del siglo Xl, sería el n. 87 procedente de la iglesia de San Stefano (BERTI, TONGIORGI, 1981, tv. CXXXVIII, fg. 132, 215-9) que abre un grupo de piezas con una decoración en su interior, de estampillas caracterizadas por su disposición en tres o cuatro anillos concéntricos, en los que son frecuentes las bandas de motivos de orlas o lunas punteadas. En este grupo se hallarían los n. 108, I 10, I 19, 123, 137, 147 y I 48 (BERTI, TONGIORGI, 198I, tv. CXXXVIIIIX, CXLI, fg. 133-6, 215-8), todos ellos decoraban la iglesia de $\mathrm{S}$. Sisto y responden tipológicamente a dos grupos claramente diferenciados: el primero lo formarían los n. 87, I 10, 108, 123 y 119 , todos ellos de perfil quebrado, con carena alta y muy abierto, con borde exvasado y 
con repie anular. El segundo grupo formal lo constituye los ataifores n. 137 y | 48, de paredes curvas y borde regruesado con ligero pie anular. Forma muy similar a la del ataifor n.2 decorado en "verde y manganeso". En su primera publicación fueron considerados como de la segunda mitad del siglo Xl y en su revisión, G. Berti concreta una cronología para todos ellos, excepto el n. 87, como del tercer cuarto del siglo XI (1997-8, 245) (Fg. 5).

La serie más moderna de ataifores con decoración estampillada estaría formada por los $\mathrm{n}$. 194, 228, 229, 233 y 235 (BERTI, TONGIORGI, 1981, fg. I38, tv.CXXXVI y CXLII, 219-220) (Fg. 6.I), encontrados todos ellos en la iglesia de San Andrea, con una cronología del primer cuarto del siglo XII (BERTI, 1997-8, 245), y en general presentan evidentes diferencias formales y decorativas respecto a los del primer grupo. Así, sus perfiles corresponden al tipo "bol" o de paredes curvas con ligero borde exvasado y con marcado repie anular y en su interior sólo presentan en su umbo un solo anillo decorado con estampillas vegetales de rosetas. De tipología similar, sería el fondo de ataifor con estampillas hallado en Savona y que ha sido datado como de los siglos XII-XIII (GARCÍA PORRAS, 1999-2000, 190, fg. 1,2).

Este último tipo de ataifores con decoración estampillada en un solo anillo, ya se había documentado en las excavaciones en Denia (GISBERT, 1985) y posteriormente se pudo confirmar que son cerámicas producidas en el alfar de la calle Teulada (GISBERT, BURGUERA, BOLUFER, 1992, 90, fg. 21), aunque los perfiles de los ataifores son algo diferentes, al presentar una ligera carena en su parte alta y el típico borde en pico de ave y no nos extraña que posean una cronología algo más moderna que los italianos, es decir del segundo tercio del siglo XII, primer tercio del siglo XIII, como son los casos de los ataifores números 20 y 21 del catálogo (GISBERT, BURGUERA, BOLUFER, 1992, I35-136). CrOnología que coincide con el grupo de estampilladas bajo cubierta del alfar (AZUAR, 1998a, 61; AZUAR et alii, 1995, 142) (Fg. 6.2).

La cronología y el perfil de estos ataifores generan severas dudas sobre el origen de Denia del grupo de la iglesia de San Andrea, cuestión ésta necesitada de análisis metalográficos. Sin embargo, hasta el momento, en la península sólo se ha podido identificar esta producción en los alfares de Denia, en claros contextos de la segunda mitad del siglo Xll y principios del siglo XIII y con una geografía claramente valenciana, como ya definimos en su día (AZUAR, 1989, 315 6; AZUAR et alii, 1995) y en los alfares de Mandarim Chinês del arrabal occidental de Lisboa, en el que, por desgracia, sólo se han documentado los fondos decorados de los ataifores, por lo que se desconoce su forma completa, aunque la cronología de los mismos es similar a los de Denia, es decir del siglo XII (BUGALHO, FOLGADO, 200I).

Revisando en la distancia esta producción y a la vista de las investigaciones actuales en la península, hoy podemos afirmar que, -aunque fue considerada en su día como de época emiral por su similitud con las estampilladas bajoimperiales procedentes del norte de Africa (ZOZAYA, 1980; RETUERCE, ZOZAYA, 1986)-, esta producción, de estampillas en un solo anillo, no es anterior al siglo XII, como lo atestiguan su aparición en los yacimientos de Lorca (AMORES, 1986), de Murcia (AMORES, 1987) y ya, en el interior de la península, han aparecido en las excavaciones de Calatrava en su período almohade (1 185-1212) (RETUERCE, 1998, 422). Cronología ésta, perfectamente constatada arqueológicamente y que pone en duda las dataciones taifales propuestas en su día por $F$. Valdés para las encontradas en los yacimientos de Mesas de Villaverde, Calatalifa, Alcalá de Henares y en los de la provincia de Guadalajara, como Zorita de los Canes, Hita, Montarón, Peñafora, etc, así como en Badajoz (VALDES, 1985).

Confirman esta cronología de época almohade, las cerámicas estampilladas encontradas en las excavaciones urbanas de la ciudad de SeviIla (LAFUENTE, 1996), en las alcazabas portuguesas del castillo de Silves (VARELA, 1988,, 228ss) O de Mértola (GÓMEZ, 1997a, 318), con una gran variedad de repertorio de estampillas en ambos yacimientos. Es decir, creo que las investigaciones y descubrimientos de los últimos años permiten constatar la cronología almohade de esta técnica decorativa de estampillas bajo 
cubierta, insertas en una faja central en el umbo de los ataifores. Igualmente, hasta el momento sólo conocemos como centros productores los alfares de Denia y de Lisboa. Por la geografía cuantitativa de aparición de la producción dianense, podemos definirla como una producción destinada a los mercados urbanos y comercializada por vía marítima a través de los puertos de Valencia, Denia, Sevilla, llegando a Mértola remontando el Guadiana, y a Silves, a través de su antiguo estuario.

Esto es lo que sabemos de estas cerámicas con estampillas dispuestas en un solo anillo; sin embargo, no hemos encontrado, en la península, cerámicas como las del primer grupo de bacini italianos, con estampillas dispuestas en varios círculos y de una cronología de la segunda mitad del siglo XI (BERTI, 1997-8). Ahora bien, sabemos que en la península, con posterioridad a la época almohade, comienzan a producirse y distribuirse una serie de ataifores de paredes carenadas con una decoración en su interior de estampillas bajo cubierta monocroma, distribuidas en varios círculos y hasta en sus paredes superiores, de factura muy similar a las italianas, pero que en al-Andalus poseen una cronología de la segunda mitad del siglo XIII-principios del XIV, como las halladas en la ciudad meriní de Al-Binya (Algeciras),-fundada en el año 1279 y ocupada por los cristianos en I344 (TORREMOCHA, NAVARRO, SALADO, 1999 , 166-8)-, que han sido recientemente estudiadas y sistematizadas y entre ellas podemos observar los ejemplares n. 162 y 164 que disponen las estampillas sobre toda la superficie del ataifor (TORREMOCHA, OLIVA, 2002, 37, 250 y 253). LO mismo sucede con el ataifor R.E. 4640 del Museo de la Alhambra que presenta un mismo tipo formal con decoración estampillada bajo cubierta por todo su interior, llegando hasta el borde y que sabemos es de época nazarí con una cronología de los siglos XIV-XV y que se exhibió en la exposición "Arte islámico de Granada" (1995b, n.82, 289). Es decir, estos ataifores con estampillas bajo cubierta dispuestas en toda su superficie interior se documentan en la península en centros musulmanes, como la ciudad meriní de Al-Binya, o en Granada, antiguo reino nazarí, con una cronología de los siglos XIII-XIV, coincidiendo con el movimien- to cultural conocido como "mudéjar" que se desarrolló en la península en la baja edad Media, caracterizado por la incorporación de estampillas en casi todas las formas cerámicas. Por todo ello, la presencia en Pisa de bacini con esta decoración y de una cronología de la segunda mitad del siglo Xl, nos genera grandes dudas sobre que sean de procedencia andalusí, como afirma G. Berti (1997-8), a no ser que los de la iglesia de $\mathrm{S}$. Sisto sean de cronología más reciente.

\section{LAS CERÁMICAS CON VIDRIADO MONOCROMO}

El último grupo de cerámicas provenientes de al-Andalus y halladas en las iglesias de Pisa es el formado por aquellas cerámicas que presentan un vidriado o esmaltado, uniforme y monocromo por su superficie. Este grupo, según la última revisión de G. Berti constituye un conjunto que supera con mucho el centenar de bacini y con un ámbito cronológico enmarcable en el siglo XII, con contados ejemplares que podrían fecharse ya en la primera mitad del siglo XIII (BERTI, 1987-8, 245-6). De entre todos ellos, creemos poder identificar el subgrupo formado por los vidriados en verde con la presencia, en la mayoría de los casos, en el umbo de una espiral en relive, a modo de marca de alfarero. Este subgrupo fue descrito por G. Berti y L. Tongiorgi, como del primer cuarto del siglo XII (198I, fg. |42-3, 221) y está formado por los n. 177, I78, I81, 186, 187, I91 y 193 de la iglesia de San Silvestro y de la iglesia de San Andrea provendrían los n. 204, 217 , 231, 247 y 248 . Estos responden a dos tipos muy claros, el grupo de ataifores de paredes bajas y borde en ala, correspondientes a la fg. I 42 y los de paredes curvas y altas, tipo "bol" con ligero borde exvasado, agrupados en la fg. I 43 (BERTI, TONGIORGI, 198I, 22I) (Fg. 7.I).

Al estudiar las producciones del alfar almohade de Denia ya pusimos de relieve como se podía identificar como marca de alfar aquellos ataifores con espiral en el umbo (AZUAR et alii, 1995, 142) y que precisamente encontramos en estos de Pisa con formas también muy similares y que, curiosamente, responden al mismo 
tipo de los ataifores o que portan la misma decoración estampillada en un anillo central (Fg. 7.2).

Con todo ello, se puede identificar a estos bacini como provenientes de los alfares de Denia, con la diferencia de que su cronología en Italia, de la primera mitad del siglo XII, es por lo menos medio siglo anterior a la cronología de estas producciones en Denia (GISBERT, BURGUERA, BOLUFER, 1992).

\section{CENTROS DE PRODUCCIÓN ANDALUSÍES: MALLORCA, MÁLAGA, MURCIA Y DENIA}

Gracias a los trabajos y a los análisis llevados a cabo por el profesor T. Mannoni, desde los laboratorios mineralógicos de la Universidad de Génova, en colaboración con la profesora Graziella Berti, con quien desarrolló un intenso programa de estudios y análisis de los bacini hallados en Pisa (BERTI, MANNONI, 1991; 1995; 1997), y que les ha permitido, como se ha visto, identificar una serie de producciones cerámicas que podrían provenir de complejos alfareros andalusíes, los cuales pasarmos a analizar.

\section{VIla) La producción en "verde y manganeso" de Mallorca}

Como se ha visto anteriormente, dentro del conjunto de cerámicas decoradas con esta técnica se pudo identificar un grupo bastante importante de ataifores como procedentes de Mallorca y que fueron dados a conocer en una publicación conjunta de los profesores G. Berti, G. Rosselló y E. Tongiorgi (1986). Esta primera identificación se basaba en la similitud estilística y decorativa existente entre varios ataifores hallados en Mallorca y los ejemplares Pisanos. Caracterizados por su decoración recargada, con motivos vegetales y sobretodo, por la excepcionalidad de representar escenas de barcos. En cuanto a su forma, hay que resaltar otro rasgo y es su característico perfil quebrado con su desarrollado repie anular; rasgos todos ellos que fueron motivo de un análisis posterior debido al propio Guillermo Rosselló (1988) quien, al efectuar una síntesis comparativa de las formas asociadas a las cerámicas decoradas en "verde y manganeso" en al-Andalus, ponía de relieve las diferencias existentes entre las consideradas como producidas en Mallorca y las del resto de al-Andalus. De tal forma que, a estos ataifores encuadrados dentro de su tipo II, llega a considerarlos como una producción de clara influencia oriental, con un marco de difusión Este-Oeste (Ifriqiya-Mallorca-Valencia), no constatada o documentada en la península (ROSSELLÓ, 1987, 133) y claramente encuadrable en el período Taifa (siglo XI) de la isla, con una desaparición brusca de la producción a finales de siglo (ROSSELLÓ, 1987, 128).

Ciertamente, la simple comparación formal con los tipos identificados de Madina Az-Zahra (ESCUDERO, 1988-90), de Madina Elvira (CANO, 1993), así como con los ataifores procedentes del alfar de san Nicolás de Murcia (NAVARRO, 1990) etc. nos permite concluir que nos hallamos ante ataifores totalmente diferentes y más desarrollados o evolucionados que los de paredes curvas y bajas, que en la mayoría de los casos no presentan pie, correspondientes al tipo "O" de G. Rosselló, el más antiguo y de cronología de fines del siglo $X$-primer cuarto del siglo XI (ROSSELLÓ, 1987) (Fg. 8).

Con todo ello, nos encontramos con una producción de ataifores perfectamente representada en la zona de Pisa que proceden de un centro alfarero de la isla de Mallorca, con una cronología en Italia del último cuarto del siglo $\mathrm{X}$-primer cuarto del siglo $\mathrm{XI}$, ratificada por la propia profesora Graziella Berti en sus últimas publicaciones (BERTI, 1997-8, 243; 2000), que en al-Andalus presenta grandes interrogantes, como dijo G. Rosselló en su primera síntesis efectuada sobre el tema y en el que defendía su primera cronología (ROSSELLÓ, 1978) para esta producción como propia de la Taifa de Mallorca y por tanto de pleno siglo XI (ROSSELLÓ, 1987), ratificando esta cronología en la exposición internacional que sobre las cerámicas en "verde y morado"se organizó en Marsella en 1996 (ROSSELLÓ, 1996, I I0, nº 85). 


\section{VIIb) EI posible taller de Málaga}

(Fg.: 2)

Dentro del grupo de producciones en "verde y manganeso", los análisis metalográficos efectuados recientemente por G. Berti y T. Mannoni $(1997,435)$ les ha permitido aislar e identificar un posible centro de producción en el área de Málaga, de donde, como ya analizamos, provendría el n. 2 con decoración zoomórfica muy similar en forma y tratamiento al conocido ataifor hallado en las excavaciones de Mértola (Portugal) (TORRES, 1987; GÓMEZ, 1998, n. 62 , 100).

La singularidad formal y decorativa de estos ataifores permite diferenciarlos del compacto grupo de ataifores de perfil quebrado, procedentes sin discusión de alfares mallorquines. De la misma ciudad de Mallorca, al realizar excavaciones en el palacio de la Almudayna aparecieron varios fragmentos cerámicos de un ataifor que permitieron a Guillermo Rosselló su reconstrucción y su posterior publicación (ROSSELLÓ, 1985), en la que lo identificó por su característico perfil abierto de paredes altas y con la técnica del reticulado de los rellenos de la figura central (Fg. 9. 4) como adscribible a este grupo de producción en "verde y manganeso". El conjunto se completaría con el hallazgo posterior del famoso ataifor de la "nave", en las excavaciones de El Fortí de la ciudad de Denia (GISBERT, BURGUERA, BOLUFER, 1992, n० I, 119) (Fg. 9. 3).

Hasta aquel momento esta serie de ataifores de similar perfil y tratamiento decorativo fue considerada como procedente de Kairauan como así lo consideraban G. Berti y L. Tongiorgi (1981) y el propio G. Rosselló (1985) en atención a sus evidentes similitudes con los ejemplares tunecinos publicados en su día por el profesor A. Daoulatli (1979). Tras los análisis efectuados posteriormente por G. Berti y T. Mannoni, como se ha dicho, defendieron y así lo reitera la profesora G. Berti (1997-8) el origen malagueño de esta producción, aunque tras el descubrimiento y excavación del alfar califal de Dénia, el mismo J. A. Gisbert ha venido a plantear el que esta producción podría proceder de este centro alfarero (GISBERT, 2003, 75-6).
El debate está abierto, de tal manera que la misma Susana Gómez Martínez en su inédita tesis doctoral sobre "La cerámica islámica de Mértola. Producción y comercio", leída el pasado mes de Septiembre en la Universidad Complutense de Madrid y a la que he tenido acceso al formar parte del tribunal, y por lo que agradezco el que me dé la oportunidad de dar a conocer su revisión del origen o procedencia de este extraordinario ataifor, del que viene a resucitar su posible origen norteafricano.

Indiscutiblemente, el origen de esta serie cerámica está demandando una necesaria revisión de sus pastas y el que se contrasten los datos mineralógicos de los laboratorios italianos, con los obtenidos de los alfares de Denia, lo que permitirá a la postre identificar con claridad la procedencia de esta excepcional producción, así como su cronología.

\section{VIIc) Los alfares de "loza dorada" y “cuerda seca" de Murcia (Fg.: 3)}

Los análisis metalográficos han sido la prueba determinante de la existencia de un taller o centro productor de loza dorada en Murcia. Análisis que fueron corroborados en Italia (BERTI, MANNONI, 1995) y que han confirmado la noticia dada por las fuentes árabes, en concreto por Ibn Sa'id al-Magribi, referentes a la existencia a finales del siglo XII de talleres en donde se hacía loza dorada en la ciudad de Murcia.

Aquellos primeros análisis permitieron a J. Navarro identificar como murcianos una serie de ataifores de perfil quebrado y fechados en la segunda mitad del siglo XII, con una geografía centrada en Murcia, Valencia y Mallorca (NAVARRO, 1986), sólo representado en Italia por un ejemplar, -el n. 165 (BERTI, TONGIORGI, 198I, fg. 222, 262)-, el cual posee una cronología deposicional medio siglo anterior. Sin embargo, la continuación de los estudios metalográficos han llevado a considerar como murcianos al grupo mayoritario de éstos, caracterizados por su perfil curvo y con similar cronología (BERTI, 1997-8, 246).

Con este característico perfil curvo son la mayoría de los ataifores decorados en reflejo metálico que se conocen en al-Andalus y que 
se engloban dentro del tipo Illb de la tipología de G. Rosselló, con una cronología de finales del siglo XII, principios del siglo XIII (1983, 1983a) , por lo que no es extraño que el ejemplar de ataifor de loza dorada procedente de la "cova dels Amagatalls" de Mallorca sea formal y decorativamente muy similar al n. 364 (BERTI, TONGIORGI, 198I, fg. 22, 268) que también posee esta cronología de principios del siglo XIII (BERTI, 1997-8).

A la problemática de la diferencia cronológica entre los ejemplares hallados en Italia y los andalusíes, hay que añadir, en este caso, el que hasta el momento desconocemos: cual y donde estaría este complejo alfarero en Murcia, ya que entre los conocidos de época almohade no se ha podido documentar esta producción de "loza dorada" (AZUAR, 1998a; MUÑOZ, 1993). Complejo o centro en donde podrían también producirse cerámicas decoradas a la "cuerda seca", según confirman los análisis metalográficos efectuados en Italia, en donde se ha podido constatar (BERTI, MANNONI, 1995, 403) que los bacini de "loza dorada" números 218 y 249 , tendrían la misma composición que los de "cuerda seca" números 154 y 63 y a su vez, mineralógicamente hablando, serían idénticos a los ataifores en "cuerda seca" murcianos $n^{\circ}$ 324, 477 y 478, del catálogo de cerámicas publicado por J. Navarro y de una amplia cronología de los siglos XI-XII (1996a, I52 y 222).

En conclusión, los datos mineralógicos permiten afirmar que la gran mayoría de las lozas doradas documentadas en las iglesias de Pisa provienen de un centro productor, no identificado, de Murcia, del que también pudieron fabricarse algunos ataifores decorados con la técnica de la "cuerda seca total" y que, en conjunto, permiten aventurar que este centro o centros alfareros estuvieron funcionando a lo largo del siglo XII, con perduración hasta la primera mitad del siglo XIII.

\section{VIId) El alfar almohade de Denia}

El alfar de Denia es, hasta la actualidad, el único alfar de época almahode excavado en extensión y con toda su producción cerámica perfectamente publicada (GISBERT, BURGUERA, BOLUFER, 1992) lo que nos permite identificar entre los bacini una serie de ellos como procedentes de este alfar. Nos referimos a la serie con estampillas bajo cubierta verde, dispuestas en un solo anillo en su fondo y que serían, como se ha visto, los números 194, 228, 229, 233 y 235, todos ellos procedentes de la iglesia de San Andrea de Pisa y con una cronología del primer cuarto del siglo XII (BERTI, 19978, 245). Por el contrario estos ataifores con estampillas bajo cubierta se localizan en el nivel superior del alfar de Denia, con una cronología de la segunda mitad del siglo XIl y con una geografía de aparición en la península claramente meridional y costera, ya que se han documentado en Valencia, Murcia, Sevilla, Algeciras, Mértola, Silves y Ceuta.

De este mismo centro alfarero y con idéntica cronología serían los esmaltados en monocromo verde y que presentan, como rasgo propio e identificador, en su umbo una "espiral" en relieve. Estos serían los n. 177, 178, I81, I86, 187, 191 y 193, procedentes de la iglesia de S. Silvestro y los números 204, 217, 231, 247 y 248 que precisamente proceden de la iglesia de San Andrea, con una cronología de la primera mitad del siglo XII (BERTI, 1997-8, 245).

A la vista de estos datos, es razonable pensar que del alfar de Denia pudieron proceder la mayoría de los bacini o ataifores con decoración estampillada bajo cubierta en un solo anillo y aquellos monocromos con una espiral en relieve en su fondo que, en conjunto, constituyen cuantitativamente el lote más importante y el más uniforme, en cuanto se refiere a sus formas, ya que responden en su mayoría al tipo de paredes curvas y repie anular. Por último, es necesario señalar la diferencia cronológica existente entre las dataciones de la producción de Denia, perfectamente encuadrable entre la segunda mitad del siglo XII, primera mitad del siglo XIII, y las dataciones claramente altas de Italia, confirmadas como de la primera mitad del siglo XII. Estas evidentes diferencias, están necesitando una revisión, así como de los necesarios análisis metalográficos para confirmar la presencia de las producciones de Denia entre los bacini italianos. 


\section{Una necesaria revisión}

Han transcurrido más de veinte años desde la publicación de la monumental investigación sobre los bacini de las iglesias de Pisa y más de cinco desde que la profesora G. Berti publicara su última revisión y actualización sobre las importaciones andalusíes y todavía no ha habido una necesaria respuesta a los importantísimos hallazgos e identificación que ha realizado, en colaboración con el profesor Tiziano Mannoni, de los diversos centros de producción de las cerámicas provenientes de al-Andalus.

Gracias a estas investigaciones, ratificadas por los datos arqueométricos y mineralógicos, se documentaron, y así está asumido por la investigación internacional, tres centros de producción en al-Andalus: Mallorca, Málaga y Murcia. La identificación de la producción de ataifores mallorquina fue ratificada gracias a los estudios realizados conjuntamente con Guillermo Rosselló Bordoy, como se ha visto, aunque la coherencia formal de la serie, con ataifores de perfil quebrado y pies desarrollados, no dejaba dudas de la originalidad de la producción, totalmente distanciada y desvinculada de las producciones califales en "verde y manganeso" procedentes de cualquiera de los centros alfareros de la península. Esta evidente diferencia, llevaba al propio G. Rosselló a considerar seriamente un influjo oriental, con un marco de difusión este-oeste y una cronología para la producción algo posterior a la cronología deposicional propuesta por los italianos, es decir, esta producción no sería de fines del siglo $\mathrm{X}$-principios del siglo $\mathrm{Xl}$, sino propia del momento de esplendor de la Taifa de Mallor$\mathrm{ca}$, es decir de pleno siglo $\mathrm{Xl}$, y sin continuidad, desapareciendo con la taifa a finales del siglo Xl.

Situación muy diferente es la que atañe a la otra producción de ataifores en "verde y manganeso" y que gracias a los análisis mineralógicos efectuados por T. Mannoni, permitieron a la profesora G. Berti identificarla como otra producción de origen andalusí, desdiciéndose de su primera interpretación como producción Tunecina. Nos estamos refieriendo a la serie de ataifores de paredes rectas y abiertas con la característica técnica de relleno, utilizando los reticulados y de la que conocemos hasta el momento cuatro ejemplares, tres de ellos hallados en Mértola, Denia y la misma Mallorca, como se ha visto. La producción fue considerada por los italianos como procedente de Málaga, sin embargo, el hallazgo de los alfares califales de Denia, han llevado a plantear la hipótesis de que pudieran proceder de sus hornos.

El tema está abierto a falta de los necesarios análisis, pero lo que sí está claro es que el origen malagueño de esta producción, según los datos mineralógicos, difícilmente se sostiene, así como hay muchas dudas, por falta de análisis, sobre que Málaga pudiera identificarse como centro productor de las ricos y variadas serie de cerámicas en "cuerda seca" halladas en el interior de su alcazaba. Todo ello, nos lleva a demandar la necesaria investigación sobre el origen de estas producciones y de estos posibles centros de producción, todavía hoy no descubiertos.

Lo que no ofrece lugar a dudas es que al menos la serie de loza dorada de ataifores de borde en ala, se fabricaba en Murcia, ratificando así la información aportada por las crónicas árabes. Sin embargo, esta importantísima investigación y descubrimiento empezado por Julio Navarro en el año 1986, no ha tenido continuidad y hoy en día, seguimos sin saber dónde estaban estos alfares y si de ellos proceden la serie almohade de ataifores de perfil curvo, la más abundante en la península y que se importó a mediados del siglo XIII a Italia.

Según los datos y análisis mineralógicos estos mismos alfares murcianos debieron producir cerámicas a la "cuerda seca total"; producción todavía no identificada claramente, aunque hoy en día sabemos de esta producción en los alfares de Zavellá (Mallorca), de Almería, de Denia, de Toledo, etc. y en todos ellos con una cronología no anterior al siglo Xl, lo que está en clara contraposición con la cronología de origen para los bacini de las iglesias de Pisa que la profesora G. Berti sigue considerándolos, atendiendo a la cronología de los edificios, como de fines del siglo $X$ y principios del siglo XI. Cuestión ésta no resuelta, que llevo reclamando 
desde el año 1995 y que parece no importar a mis colegas especialistas que tratan esta producción en la península.

El descubrimiento y la excavación de los alfares califales y almohades de la ciudad de Denia creo que ha venido a ampliar nuestro conocimiento de los centros de producción andalusíes, así como a identificar por primera vez, de forma rigurosa, una producción de época almohade de al-Andalus. Esto permite el plantear la posibilidad de que algunas producciones en "verde y manganeso" identificadas en Italia pudieran provenir de estos alfares, algo lógico, si pensamos que la Taifa de Denia en el siglo Xl estaba plenamente inmersa en la dinámica comercial del mediterráneo. Igualmente, el conocimiento de las producciones de época almohade me ha permitido, desde el análisis tipológico, el proponer la identificación entre los bacini, de las series de ataifores decorados con decoración estampillada bajo cubierta verde y los monocromos con espiral en su umbo, como procedentes de Denia. Cuestión ésta pendiente de un necesario contraste mineralógico.

Por último, creo necesario un contraste de las dataciones de estas producciones andalusíes en Italia y en la península; ya que en la actualidad se sigue admitiendo que la cronología deposicional de estas cerámicas en Italia es un siglo anterior a la de su origen en al-Andalus. Cuestión ésta imposible, aunque si es cierto que como nos vamos acercando hacia los siglos XII y XIII las cronologías se igualan. Esta extraña horquilla cronológica, admitida internacionalmente, exige una respuesta y una reflexión de los que nos dedicamos a la investigación de las cerámicas de al-Andalus.

\section{BIBLIOGRAFÍA}

ABULAFIA, David (1985): "The Pisan bacini and the medieval mediterranean economy: a historian's viewpoint", B.A.R. International series, 246, (London), 287-302.

ABULAFIA, David (1987): Italy, Sicily and the Mediterranean, I 100 - 1400. London.
ACIÉN, Manuel (1990): "Hornos alfareros de época califal en el yacimiento de Bezmiliana" Fours de potiers et "testares" médiévaux en Méditerranée Occidentale. Casa de Velazquez. (Madrid), I3-27.

ACIÉN, Manuel. (1996): "Almeria", Le vert \& le brun de Kairouan à Avignon, céramiques du Xe au XIVe siècle. Marseille, $21-2$.

AGUADO, José (1983): La cerámica hispanomusulmana de Toledo. Madrid.

AGUADO, José et alii (1990): "El testar del puente de San Martin (Toledo)" Fours de potiers et "testares" médiévaux en Méditerranée Occidentale. Casa de Velazquez. (Madrid), I17-130.

AMORES, Remedios (1986): "Cerámica vidriada con decoración estampillada de Lorca (Murcia)", II CMMO, (Toledo), 4I7-20.

AMORES, Remedios (1987): "Cerámica estampillada de Murcia: estudio tipológico" Boletín de la Asociación Española de Orientalistas, XXIII, (Madrid), 263-I I8.

AZUAR, Rafael (1989): Denia Islámica. Arqueología y poblamiento, Alicante.

AZUAR, Rafael (1992/3) : "La Taifa de Denia en el comercio mediterraneo del siglo XI" A.U.A.Historia Medieval, 9 (Alicante), 39-52.

AZUAR, Rafael (1998): "Al-Andalus y el comercio mediterráneo del siglo XI, según la dispersión y distribución de las producciones cerámicas", La península Ibérica y el Mediterráneo entre los siglos XI y XII, Códex Aquilarensis, 13 (Aguilar de Campoo -Palencia), 5।-78.

AZUAR, Rafael, (1998a): "Alfares y testares del Sharq alAndalus (siglos XII-XIII). Producción, tipología y distribución", Ceràmica medieval i postmedieval. Universidad de Barcelona. (Barcelona), 57-7I.

AZUAR, Rafael (2004): "Las técnicas constructivas y la fortificación almohade en al-Andalus", Los Almohades, (Sevilla) 57-74.

AZUAR, Rafael (2004): "Rutas y comercio de al-Andalus con las repúblicas italianas de Génova, Pisa y Amalfi, de los siglos XI al XIII" IV Seminario Internacional ANSER, Rotte e porti del mediterraneo dopo la caduta dell'impero romano d'occidente (Génova) (en prensa).

AZUAR, Rafael et alii (1995): "Cerámica tardo-andalusí del País Valenciano (primera mitad del siglo XIII)", Ve Colloque sur la Céramique Médiévale (Rabat), 140-170.

BENENTE, Fabrizio; GARDINI, Alessandre (1993): "I bacini ceramici della Liguria" XXI Covegno Internazionale della Ceramica (Albisola), 67-99.

BERTI, Graziella (1995): "Le ceramiche", Arte Islamica. (Pisa), $83-101$.

BERTI, Graziella (1997-8): "I rapporti Pisa-Spagna (alAndalus, Maiorca) tra la fine del $X$ ed il $X V$ secolo testimoniati dalle ceramiche", XXXI Covegno Internazionale della Ceramica (Albisola), 24I-253. 
BERTI, Graziella (2000): "Pisa: ceramiche e commerci ( $2^{\circ}$ metà X-metà XIV s.)" I Congreso Nazionale di Archeologia Medievale, (Pisa, 1997), (Firenze), 346-35I.

BERTI, Graziella; GELICHI, Sauro (1992): "Mediterranean ceramics in late medieval Italy" Boletin de Arqueologia Medieval, 6, (Madrid), 23-34.

BERTI, Graziella; GELICHI, Sauro (1996): "Mille chemins ouverts en Italie", Le vert \& le brun de Kairouan à Avignon, céramiques du Xe au XIVe siècle. Marseille, 129-163.

BERTI, Graziella; MANNONI, Tiziano (199I): "Ceramiche medievali del Mediterraneo Occidentale: considerazione su alcune caratteristiche tecniche", IV CMMO (Lisboa, 1987), 163-173.

BERTI, Graziella; MANNONI, Tiziano ( 1995): "La ceramiche a 'cuerda seca' utilizzate como 'bacini' in Toscana ed in corsica", V CMMO, (Rabat, 199I) Rabat, 400-404.

BERTI, Graziella; MANNONI, Tiziano. (1997): "Céramiques de l'Andalouse décorées en 'verde y mangneso' parmi les 'bacini' de Pise de la fin du Xe siècle", La Céramique Médiévale en Méditerranée (Aix-en-Provence, 1995), 435-7.

BERTI, G.; PASTOR, J:; ROSSELLO,G.; (1993): Naves andalusíes en cerámicas Mallorquinas. Palma de Mallorca.

BERTI, G.; ROSSELLO, G.; TONGIORGI, E.; (1986): “Alcuni bacini ceramici di Pisa e la corrispondente produzioni di maiorca nel secolo Xl', Archeologia Medievale, I3, 97-I I 5.

BERTI, Graziella; TONGIORGI, Liana. (1980): "Ceramiche decorate (XI-XIV secolo) di importazione da vari centri Mediterraneo e di produzione locale sulla base della documentazione in Toscana", La Céramique Médiévale en Mediterranée Occidentale, X-Xve siècles (Valbone, 1978), Paris, 83-91.

BERTI, G.; TONGIORGI, L.; (198I): I bacini ceramici medievali delle chiese di Pisa. Roma.

BERTI, G.; TONGIORGI, L. (1986): "Considerazioni su alcuni tipi di ceramica presenti a Pisa" II CMMO, (Toledo, 1981), 421-427.

BERTI, Graziella; TONGIORGI, Ezio (1986): "Cermiche importate dalla Spagna nell'area pisana dal XII al XV secoIo" II CMMO, (Toledo, 198I), 315-346.

BUGALHO, Jacinta; FOLGADO, Deolinda (200I): "O arrabalde occidental da Lisboa islâmica: urbanismo e produçâo oleira", Arqueologia Medieval, 7 (Mértola, Portugal), |l|- $\mid 45$

CABONA, D.; GARDINI, A.; MANNONI, T., MILANESE, M. (1980): "Contributi dell'archeología medievale ligure alla conoscenze dei prodotti ceramici nel mediterraneo occidentale", La céramique médiévale en Méditerranée Occidentale. Paris. II3-123.

CABONA, D.; GARDINI, A.; PIZZOLO, O. (1986): "Nuovi dati sulla circolazione delle cermiche mediterranee dall scavo di Palazzo Ducale a Genova (secc. XII-XIV)" La ceramica medievale nel mediterraneo occidentale, Fireze. 453-482.
CANO, Carlos (1993): "La cerámica de Madînat Ilbîra", La cerámica altomedieval en el sur de al-Andalus. Universidad de Granada. Granada., 273-285.

CANO, Carlos (1996): La cerámica verde-manganeso de Madinat al-Zahrâ. Granada.

CASAMAR, Manuel, VALDES, Fernando, (1984): "Origen y desarrollo de la técnica de cuerda seca en la Península Ibérica y en el Norte de Africa durante el siglo Xl", AlQantara,V, I-2, (Madrid), 383-404.

CONTADINI, Anna (1994): "La spagna dal II/VIII al VII/XIII secolo" Eredità dell'Islam. Arte islamica in Italia., (Venezia) 105-113.

DAOULATLI, A. (1979): Poteries et céramiques tunisiennes. Institut National d'Archéolgie et d'Art. Túnez.

DÉLÉRY, Claire (2003): "Perspectives méthodologiques concernant l'étude de la céramique de cuerda seca en al-Andalus (IX-XIV s): d'un objet archéologique a un objet historique" Arqueologia Medieval, 8, (Mértola),193-236.

ESCUDERO, José (1988-90): “La cerámica decorada en 'verde y manganeso' de Madinat al-Zahra", Cuadernos de Madínat al-Zahrâ', 2, (Córdoba),|27-|6|.

FERNÁNDEZ, Emilio A. (200I): Los silos en la arqueología Ceutí (I). Instituto de Estudios Ceutíes. Ceuta.

FLORES, I.; MUÑOZ, Ma DEL M.; LIROLA, J.; (1999): "Las producciones de un alfar islámico en Almería" La cerámica andalusí. 20 años de investigación. (Jaén, 1977). Arqueología y Territorio Medieval, 6, (Jaén), 207-240.

FRONDONI, A.; MURIALDO, G.; PALAZZI, P.; PANIZA, M.; PARODI, L. (1999-2000): "Gli scavi di piazza Santa Caterina in finalborgo (Savona): primi dati sui reperti ceramici", XXXII-XXXIII Covegno Internazionale della Ceramica (Albisola), I77-I88.

GARCIA PORRAS, Alberto (1999-2000): "La cerámica procedente de la península ibérica en el Priamàr (Savona)", XXXII-XXXIII Covegno Internazionale della Ceramica (Albisola), 189-200.

GARCIA PORRAS, Alberto (2003): "Ceramiche invetriate e smaltate provenienti dalla Penisola Iberica in un borgo medievale del Ponente Ligure gli scavi di Piazza Santa Caterina in Finalborgo (Savona)" Archeologia Medievale, XXX, 243-6.

GARCIA PORRAS, Alberto (2003a): "Una aplicación SIG en el estudio de la distribución de hallazgos cerámicos. La cerámica española importada en Italia durante la baja Edad Media" Informática y Arqueologia Medieval, Universidad de Granada, 149-179.

GIRALT, Josep (1994): "Jaciment arqueològic del Pla D'Almatà" Catalunya Romànica. XVII. La Noguera. Enciclopèdia Catalana. (Barcelona), 238-243.

GIRALT, Josep (1994a): "Ceràmica islàmica de Balaguer" Catalunya Romànica. XVII. La Noguera. Enciclopèdia Catalana. (Barcelona), 247-25I. 
GIRALT, J. (1996): "Balaguer: les fours islamiques du Pla d'Almatà (Xle siècle)" Le vert \& le brun de Kairouan à Avignon, céramiques du Xe au XIVe siècle. Marseille, 22-3.

GISBERT, Josep A. (1985): "La ciudad de Denia y la producción de cerámicas vidriadas con decoración estampiIlada. El alfar de la calle Teulada", Sharq al-Andalus, 2, (Alicante) $16 \mid-174$.

GISBERT, Josep A. (1990): "Los Hornos del alfar islámico de la Avda. Montgó/calle Teulada. Casco urbano de Denia(Alicante)", Fours de potiers et "testares" médiévaux en Méditerranée Occidentale, (Madrid), 75-91.

GISBERT, Josep A. (2000): Cerámica califal de Dénia. Universidad de Alicante. Alicante.

GISBERT, Josep A. (2003): "La producción cerámica en Daniya -Dénia- en el siglo Xl", 3 Jornadas de Cerâmica Medieval e Pos-Medieval (Tondela-Portugal, 1997), 6I-77.

GISBERT, I.A.; AZUAR, R., BURGUERA,V.(199I): "La producción cerámica en Daniyya. El alfar islámico de la Avda. Montgó/Calle Teulada (Denia.Alicante)", A Cerâmica Medieval no Mediterrâneo Ocidental, (LISBOA, 1987), 247-262.

GISBERT, J.A.; BURGUERA, V.; BOLUFER, J. (1992): La cerámica de Daniya -Dénia-. Alfares y ajuares domésticos de los siglos XII-XIII. Ministerio de Cultura. València.

GOITEIN, S.D., (1967): A Mediterranean society. The jewish communities of the arab world as portrayed in the documents of the Cairo Geniza. I: Economic foundations, London.

GÓMEZ, Susana (1994): "La cerámica verde y morado de Mértola (Portugal)" Arqueologia Medieval, 3, (Mértola), I13-132.

GÓMEZ, Susana (1997): "Loiça dourada de Mértola", Arqueologia Medieval, 5 (Mértola), 137-162.

GÓMEZ, Susana (1997a): "Cerámica decorada islámica de Mértola-Portugal (ss. IX.-XIII)" La céramique médiévale en Méditerranée (Aix-en-Provence), 31 I-325.

GÓMEZ, Susana (2002): "Cerámica". Arte Islâmica. Museu de Mértola. Mértola (Portugal), 107- 167.

GÓMEZ, Susana (2003): "Producciones cerámicas en la Mértola Islámica", VIle Congrès Internacional sur la Céramique Médiévale en Méditerranée (Thessaloniki, 1999), Athènes, 653-658.

GÓMEZ, Susana (2004): La cerámica islámica de Mértola. Producción y comercio. Mértola- Madrid 5 vols. (Tesis doctoral inédita).

GÓMEZ, Susana; DELERY, Claire (2002): Cerâmica em corda seca de Mértola. Mértola (Portugal).

GÓMEZ MORENO, M., 1940: "La loza primitiva de Málaga", Al-Andalus, V, (Madrid), 383-398.

GRANADA. ( 1995): Al-Andalus y el Mediterráneo. Granada.

GRANADA (1995b): Arte islámico en Granada. Propuesta para un Museo de la Alhambra. Granada.
KIRCHNER, Helena (2002): La ceràmica de Yâbisa. Catáleg i estudi dels fons del Museu Arqueològic d'Eivissa i Formentera. Eivissa.

LAFUENTE, Pilar (1996): "La cerámica almohade en SeviIla", El último siglo de la Sevilla islámica I | 47-I 248., Ayuntamiento-Universidad de Sevilla, 285-30।.

LERMA, Josep V. (1987): "Relaciones mediterráneas de la Valencia islámica: las cerámicas importadas", Les Illes Orientals d'Al-Andalus, (Palma de Mallorca), 339-358.

LERMA J.V. et alii (1990): La cerámica islámica en la ciudad de Valencia. II (València).

LISBOA. (1998): Portugal Islâmico. Os últimos sinais do Maditerrâneo. Lisboa.

MARSEILLE. (1996): Le vert \& le brun de Kairouan à Avignon, céramiques du Xe au XIVe siècle. Marseille.

MARTINEZ, Sergio (1990): "Hornos califales de Toledo". Fours de potiers et "testares" médiévaux en Méditerranée Occidentale. Casa de Velazquez. (Madrid), 45-6I.

MARTINEZ CAVIRÓ, B. (1995): "El arte Nazarí y el problema de la loza dorada", en Arte islámico en Granada. (Granada), 145-163.

MOSTALAC, Antonio (1990): "Los hornos islámicos de Zaragoza". Fours de potiers et "testares" médiévaux en Méditerranée Occidentale. Casa de Velazquez. (Madrid), 63-74.

MUÑOZ, Francisco (1993): "Nuevos datos sobre urbanismo y alfarería medieval en Murcia" Verdolay (Museo de Murcia), 4, 175-184.

MUÑOZ, Francisco (1996): "Murcie", Le vert \& le brun de Kairouan à Avignon, céramiques du Xe au XIVe siècle. Marseille, 24-27.

NAVARRO, Julio (1986): "Murcia como centro productor de loza dorada", III CMMO, Fireze, I29-I43.

NAVARRO, Julio (1986a): La cerámica islámica en Murcia. Murcia.

NAVARRO, Julio (1987): "Nuevas aportaciones al estudio de la loza dorada andalusí: el ataifor de Zavellá", Les Illes Orientals d'Al-Andalus. Palma de Mallorca. 225-238.

NAVARRO, Julio (1990): "Los materiales islámicos del alfar antiguo de San Nicolás de Murcia". Fours de potiers et "testares" médiévaux en Méditerranée Occidentale. Casa de Velazquez. (Madrid), 29-43.

PALAZZI, P.; PARODI, L.; MURIALDO, G.; FRONDO$\mathrm{NI}, A_{\text {.; }}$ (2003): "Archeologia di un borgo di fundazione signorile; il burgus Finarii (Finalborgo, SV) Scavi $1997-$ 200 I" III Congresso Nazionale di Archeologia Medievale, (Salerno, 2003), Firenze, 185-190.

PICÓN, M.; NAVARRO, J. (1986): "La loza dorada de la provincie de Murcie: étude en laboratoire", III CMMO, Fireze, 144-6.

PISA. (1995a): Arte Islamica. Presenze di cultura islamica nella Toscana costiera. Pisa. 
PUERTAS TRICAS, Rafael, (1989): La cerámica islámica de cuerda seca en la Alcazaba de Málaga. Málaga.

RETUERCE, Manuel (1998): La cerámica andalusí de la meseta. Madrid 2 vols.

RETUERCE, Manuel, ZOZAYA, Juan, (1986): "Variantes geográficas de la cerámica omeya andalusí: los temas decorativos", III CMMO, (Fireze), 69-128.

ROSSELLÓ, Guillermo (1978): Ensayo de sistematización de la cerámica árabe de Mallorca. Palma de Mallorca.

ROSSELLÓ, Guillermo (1983): "Nuevas formas en la cerámica de época islámica", Boletin de la Sociedad Arqueológica Luliana, 39, (Mallorca), 237-259.

ROSSELLÓ, Guillermo (1983a): "El ataifor del tipo III y sus problemas cronológicos" Homenaje al Profesor Martín Almagro Basch, IV (Madrid), I 17-I22.

ROSSELLÓ, Guillermo (1985): "Un ataifor norteafricano: un ensayo de interpretación iconográfica" Sharq al-Andalus, 2, (Alicante), 191-205.

ROSSELLÓ, Guillermo (1986): "Mallorca: comercio y cerámica a lo largo de los siglos X al XIV", II CMMO, (Madrid), 193-204.

ROSSELLÓ, Guillermo (1988): "Algunas observaciones sobre la decoración cerámica en verde y manganeso", Cuadernos de Madínat al-Zahrâ', I, (Córdoba), 125-137.

ROSSELLÓ, Guillermo (1993): "Comercio y navegación en las Baleares medievales: la información textual y arqueológica", Cuadernos de Arqueologia Maritima, 2, I77-196.

ROSSELLÓ, Guillermo (1996): "La céramique vert et brune en al-Andalus du Xe au Xllle siècle" Le vert \& le brun de Kairouan à Avignon, céramiques du Xe au XIVe siècle. Marseille, 105-117.

SOLER FERRER, Ma Paz (1990): "La cerámica con decoración de cuerda seca", La cerámica islámica en la ciudad de Valencia. II (València), 97-II4.

TORREMOCHA, A.; NAVARRO, I.; SALADO, J.B. (1999): Al-Binya, la ciudad palatina meriní de Algeciras. Algeciras.

TORREMOCHA, Antonio; OLIVA, Yolanda, (2002): La cerámica musulmana de Algeciras. Producciones estampilladas. Estudios y catálogo. Caetaria Monografias, nº I, Algeciras.
TORRES, Claudio (1987): Cerâmica islamica portuguesa. Mértola.

TORRES, Claudio, GÓMEZ, Susana (1996): "Le vert et brun au Portugal" Le vert \& le brun de Kairouan à Avignon, céramiques du Xe au XIVe siècle. Marseille, 99- 03.

TORRES, C. ; PALMA, M.P. ; REGO, M. ; MACIAS, S. (|99|) : «Cerâmica islâmica de Mértola, propostas de cronología e funcionalidade», A cerâmica medieval no mediterraneo ocidental (Mértola, Lisboa, 1987), 497-536.

W.AA. (1990): Fours de potiers et "testares" médiévaux en Méditerranée Occidentale. Casa de Velazquez. Madrid.

VENEZIA (1994): Eredità dell'Islam. Arte islamica en Italia. Venezia.

VALDÉS, Fernando (1982-3): "Al-Idrisi y los orígenes de la loza dorada en la Península Ibérica", Awraq, 5-6, (Madrid), 243-245.

VALDÉS, Fernando (1985): La alcazaba de Badajoz. Madrid.

VARELA, Rosa (1988): Cerâmicas muçulmanas do Castelo de Silves. Xelb, I (Silves).

VARELA, Rosa (|99|): "Cerâmicas almoadas do Castelo de Silves"A cerâmica medieval no mediterrâneo ocidental (Mértola-Lisboa, 1987), 387-403.

ZOZAYA, Juan (1969) : "El comercio de Al-Andalus con el Oriente: nuevos datos", Boletín de la Asociación Española de Orientalistas, 5, (Madrid), |9|-200.

ZOZAYA, Juan (1980): "Aperçu général sur la céramique espagnole", I CMMO (Paris), 265-296.

ZOZAYA, Juan (1993): "Importaciones casuales en AlAndalus: las vías de comercio", IV CAME, I, (Alicante), I I7138.

ZOZAYA, Juan (1995): "El comercio en al-Andalus", AlAndalus y el Mediterráneo. (Granada) 99- 104.

ZOZAYA, Juan ; APARICIO, Alfredo (2003): "Análisis de cerámicas andalusíes" VIle Congrès Internacional sur la Céramique Médiévale en Méditerranée (Thessaloniki, 1999), Athènes, 341-350.

ZOZAYA, ।.; RETUERCE, M., APARICIO, A., (1995):

"Cerámica andalusí de reflejo dorado: II95-12।2", V CMMO, (Rabat), 121-124. 


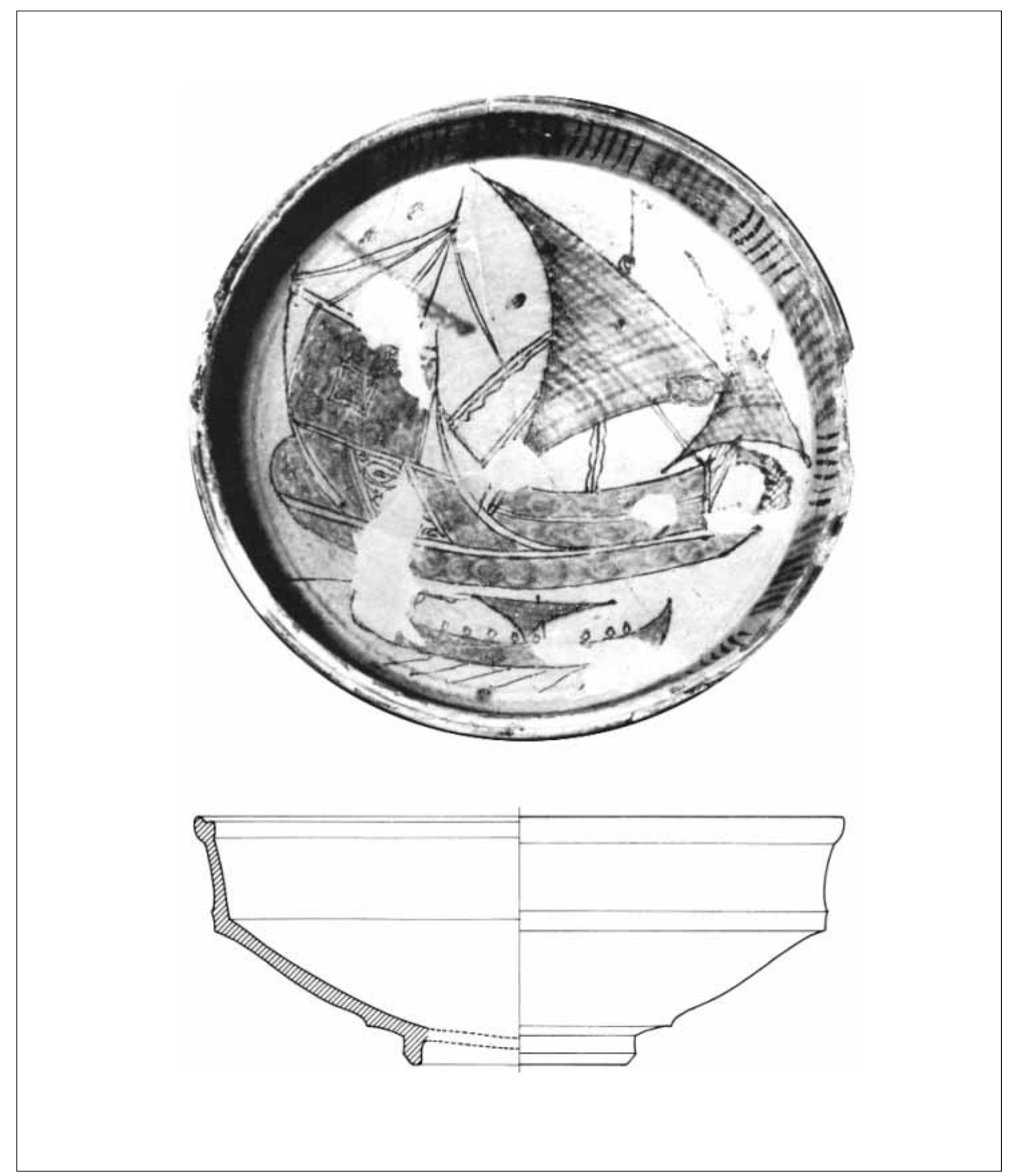

Fig. I. Serie de ataifores en "verde y manganeso" producción mallorquina. Bacini, procedente de la iglesia de San Piero a Grado de Pisa. 


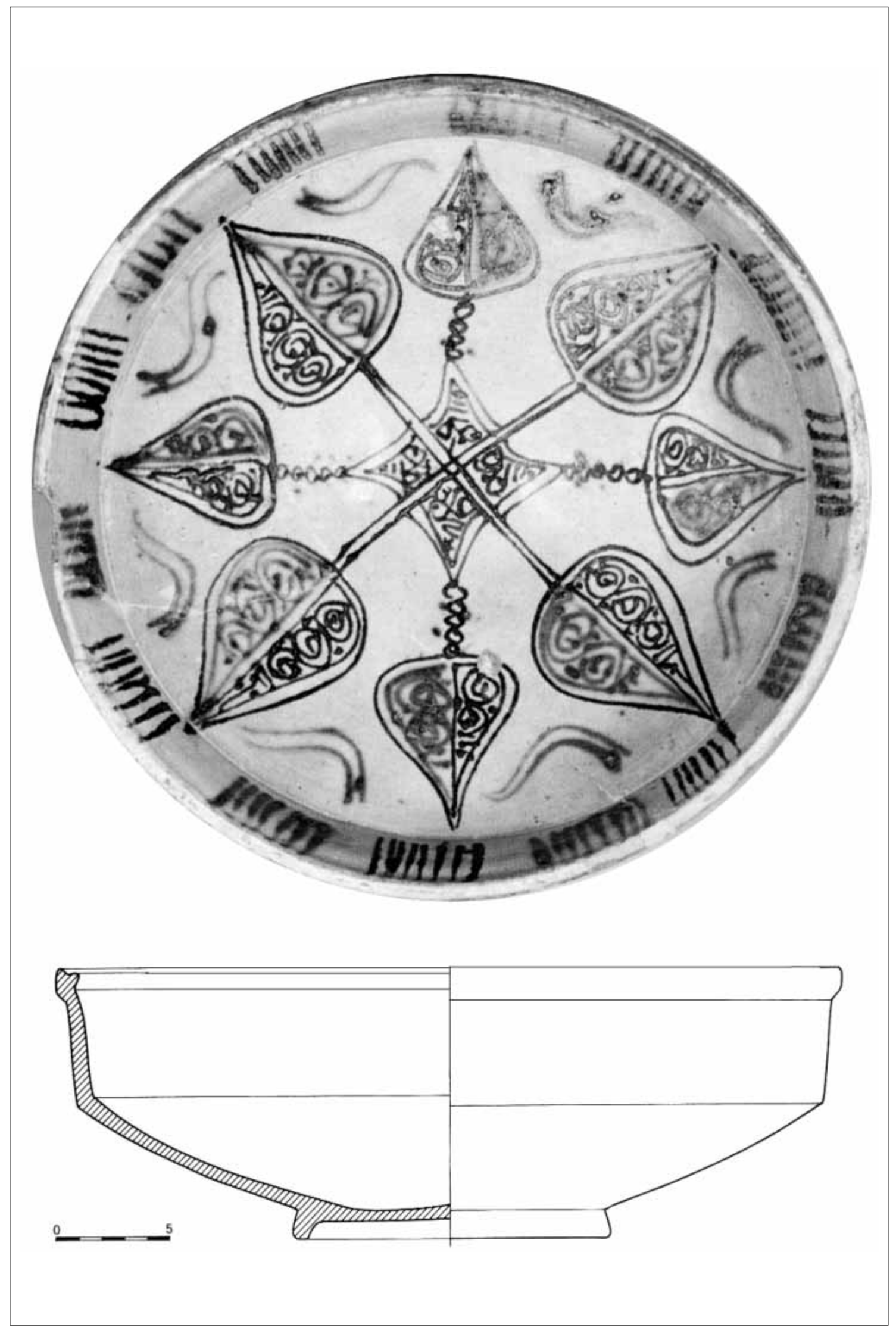

Fig. 2. Serie de ataifores en "verde y manganeso" producción mallorquina. Bacini procedente de la iglesia de San Piero a Grado de Pisa. 


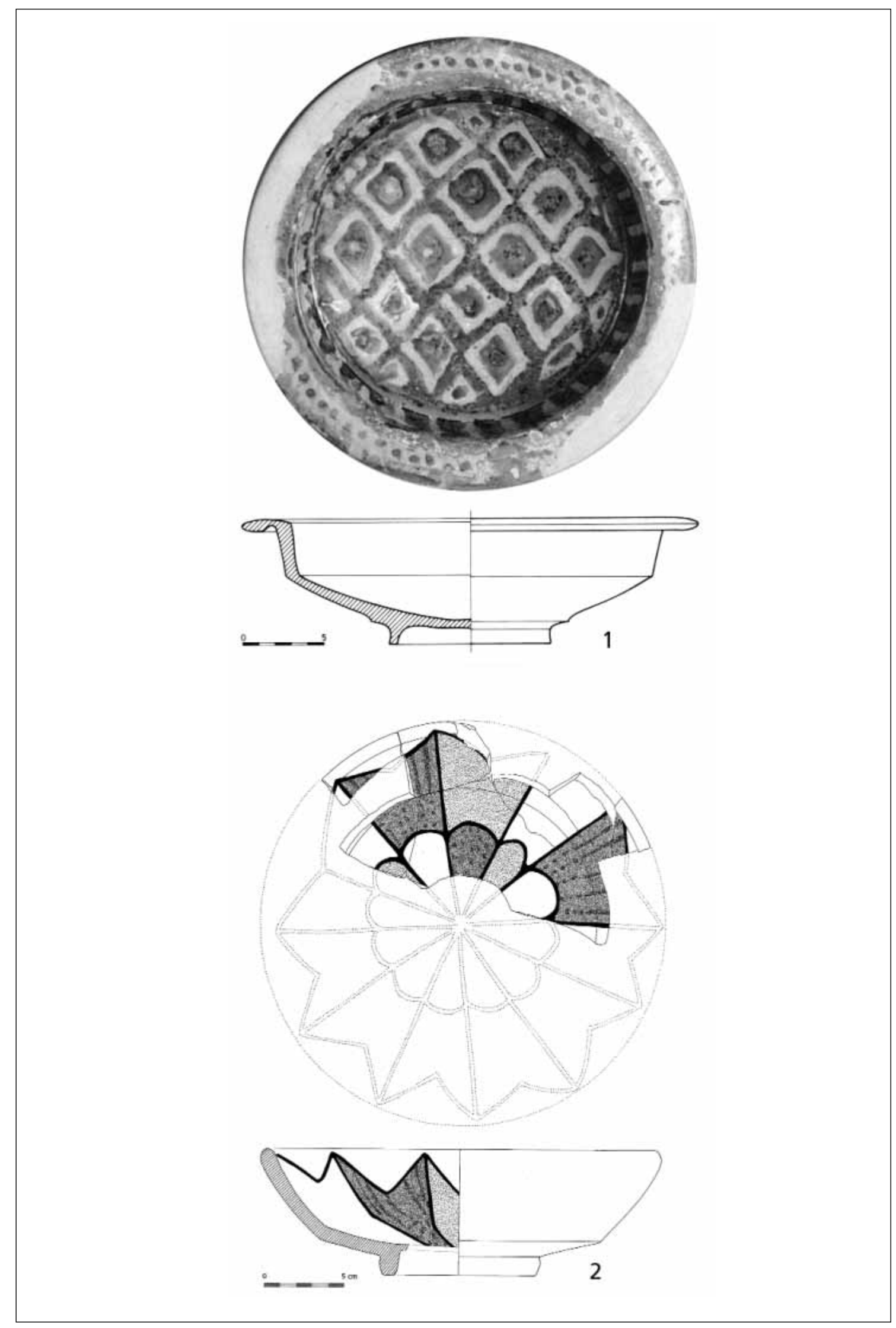

Fig. 3. Cerámicas en "cuerda seca". I.- Serie de perfil quebrado. Bacini de la iglesia de San Piero a Grado de Pisa. 2.- Serie de perfil curvo. Ataifor de la alcazaba de Mértola (Portugal). 

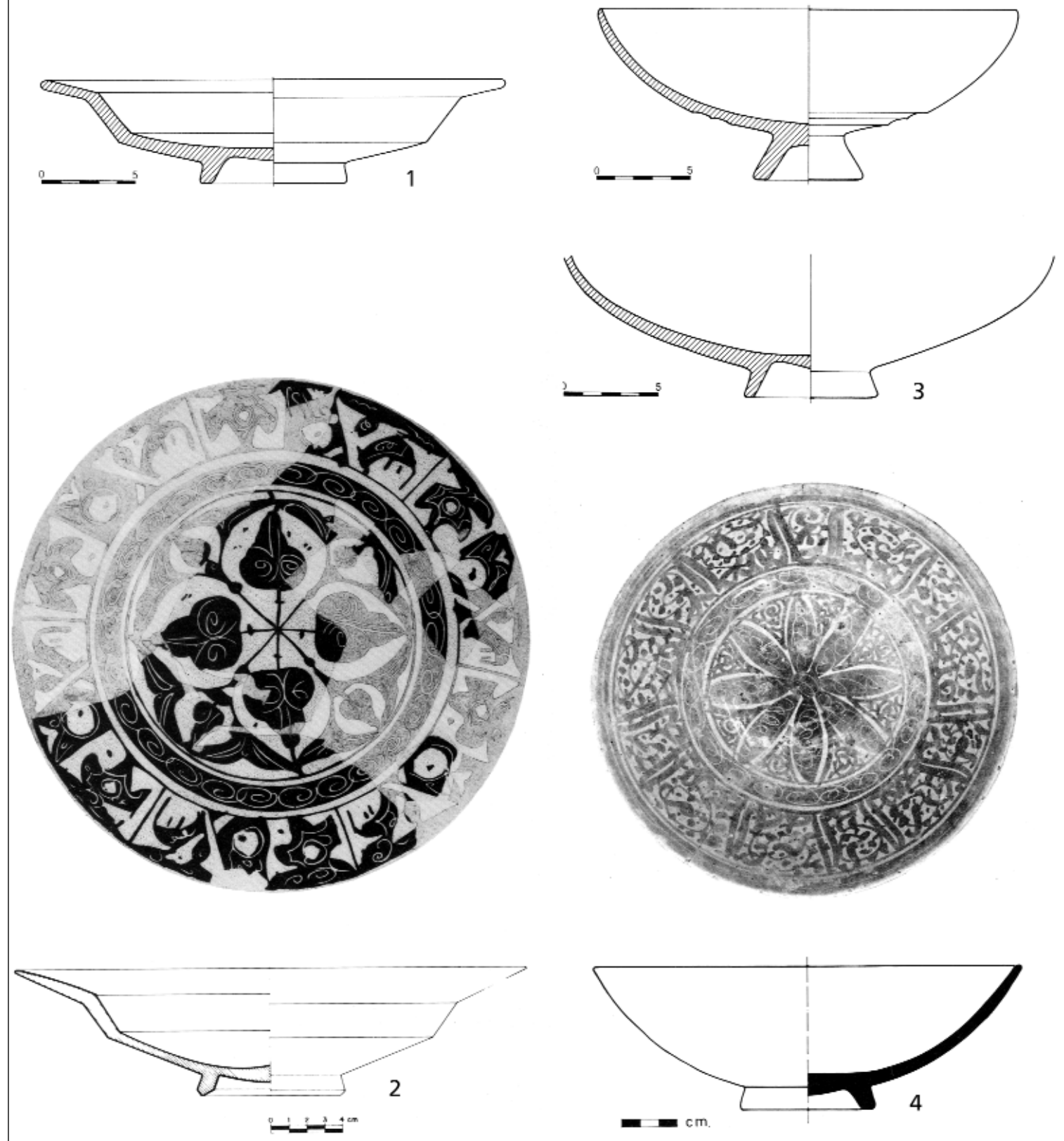

Fig. 4. Producciones de "loza dorada". Serie de perfil quebrado: I. bacini de San Sisto de Pisa. 2. Ataifor de la cl Serrano Alcázar de Murcia. Serie de perfil curvo. 3. bacini n³64 y 250 de Pisa. 4. Ataifor de la Cova dels Amagatalls de Mallorca. 

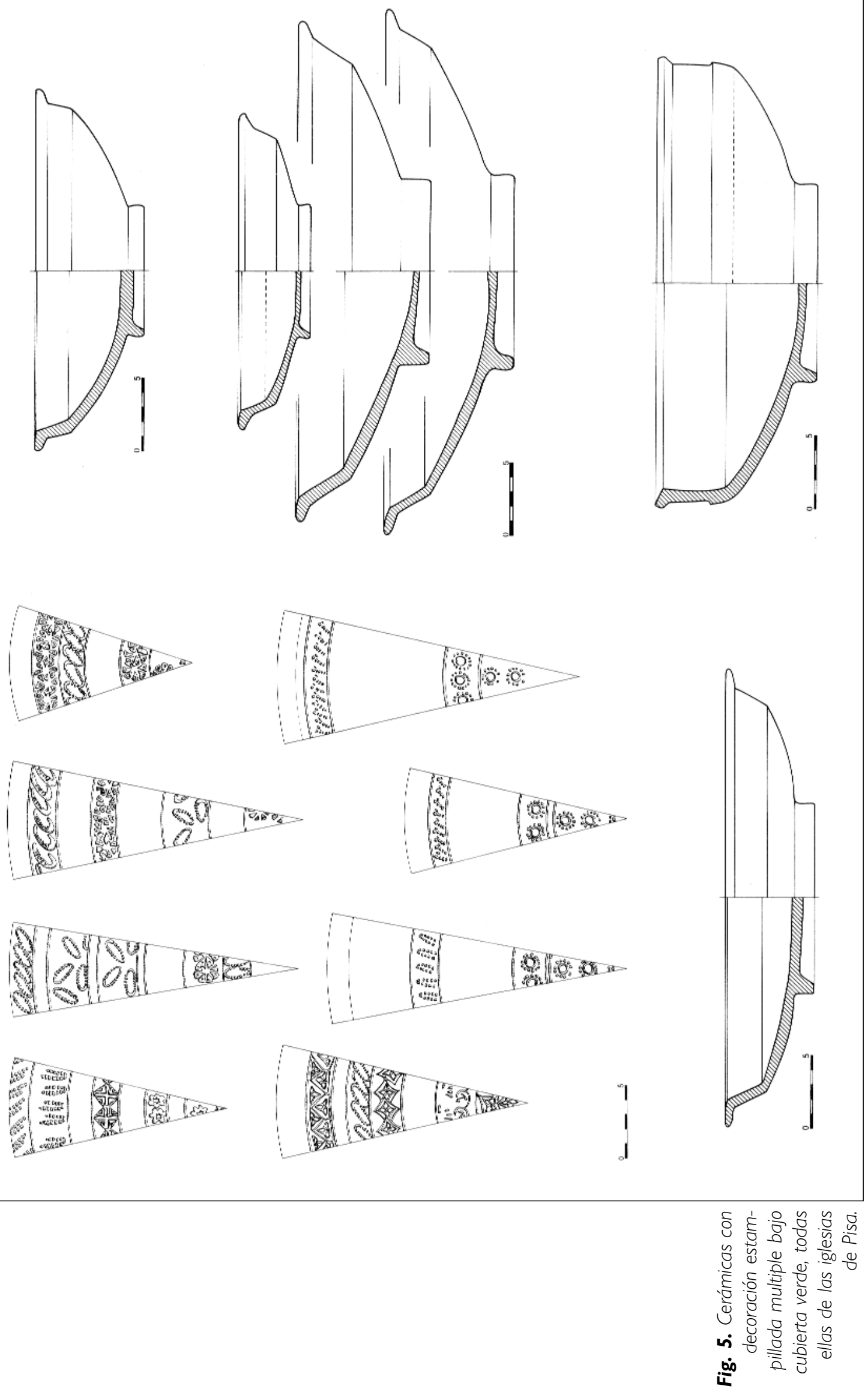


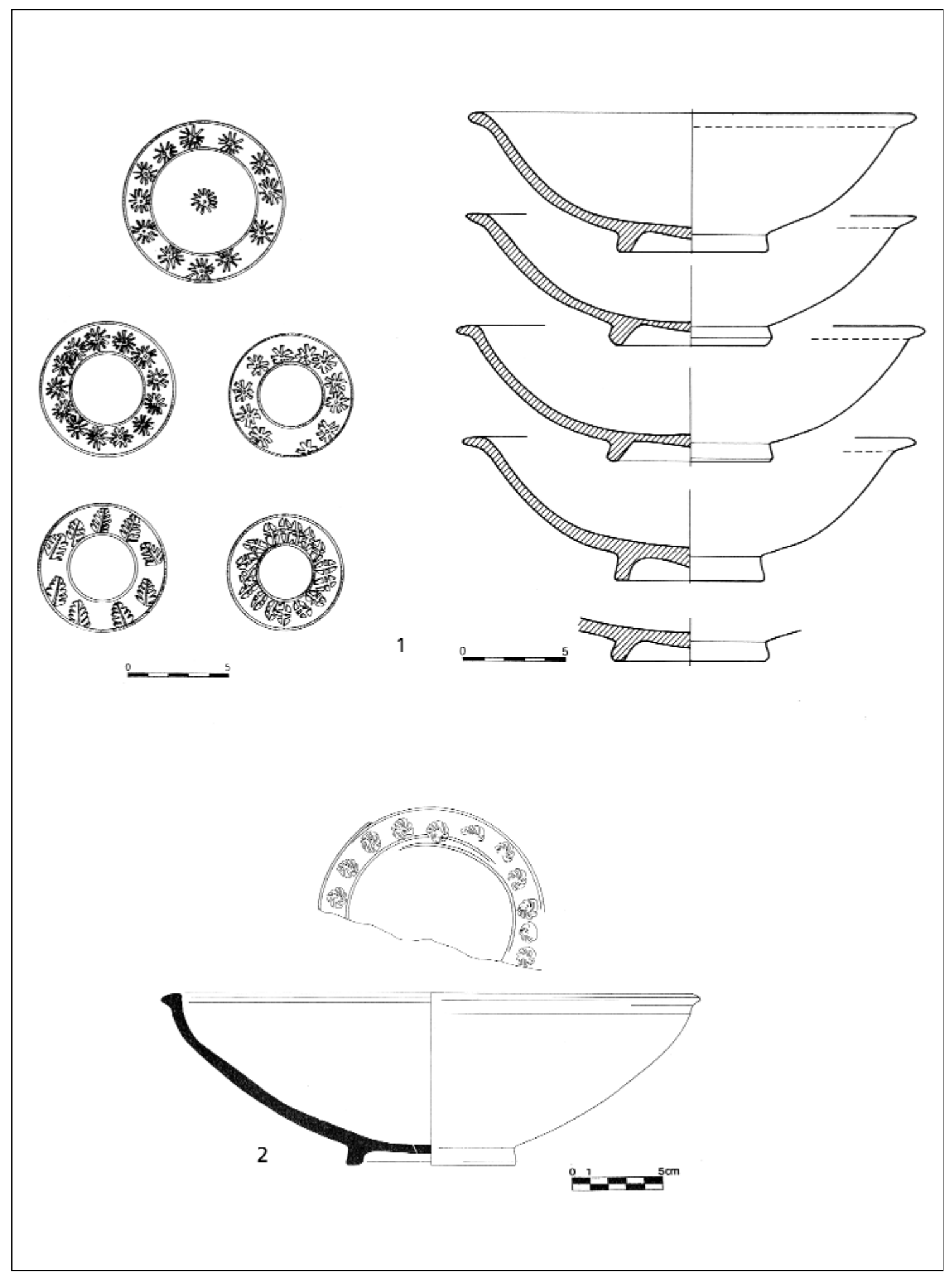

Fig. 6. Cerámicas con decoración estampillada en el anillo, bajo cubierta verde. I.- Motivos y perfiles de los bacini de Pisa. 2.- Producción del alfar de Denia. 


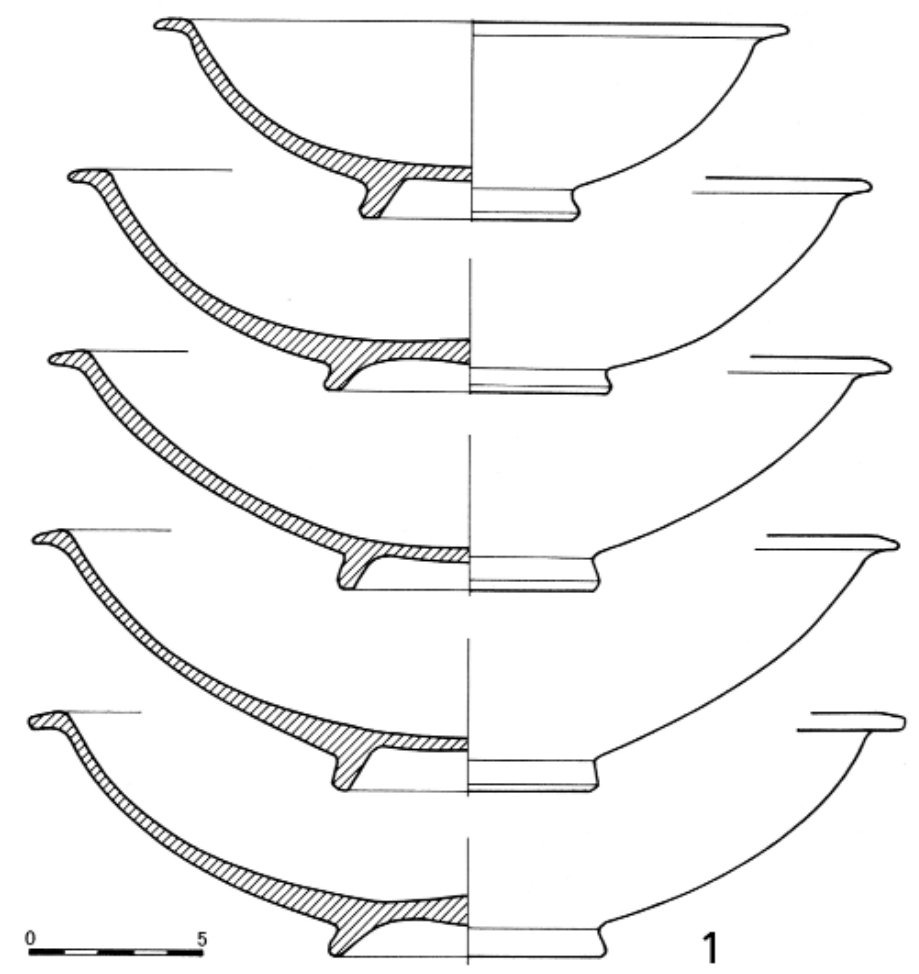

(2)

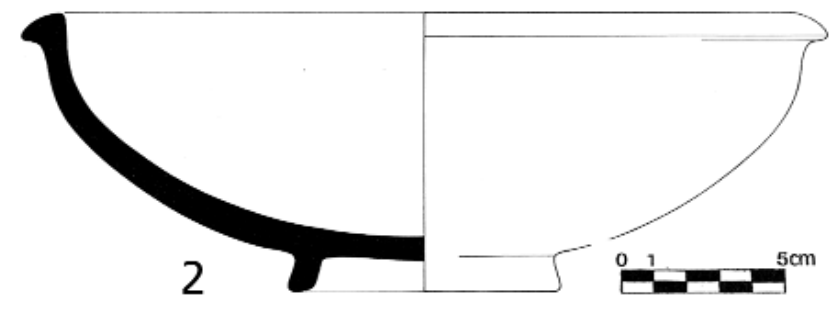

Fig. 7. Cerámicas con vidriado monocromo en verde. I.- Serie formal de los bacini de Pisa. 2. Producción del alfar de Denia. 


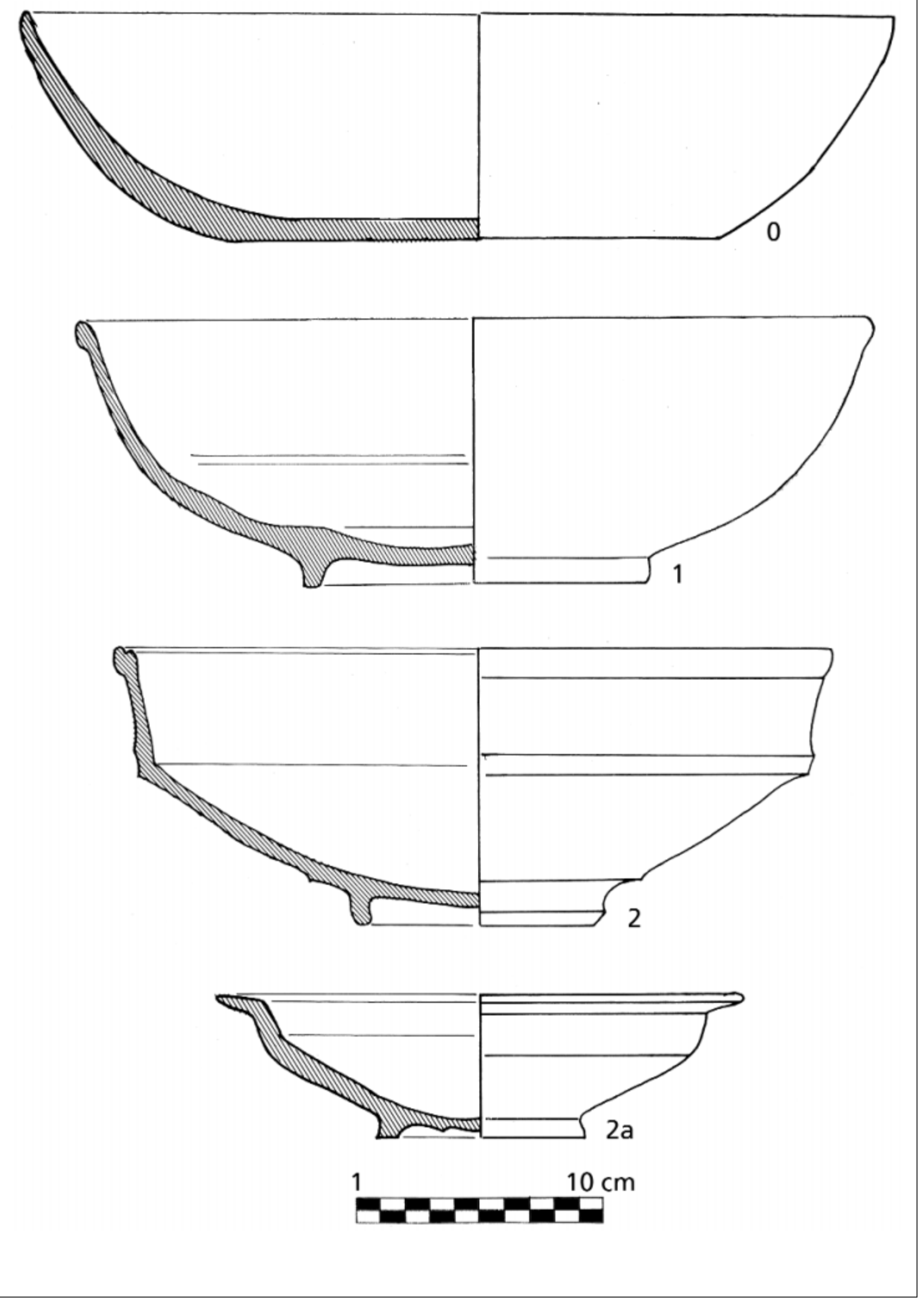

Fig. 8. Tipología de los ataifores en verde y manganeso andalusíes, según la clasificación de G. Rosselló (1988). 


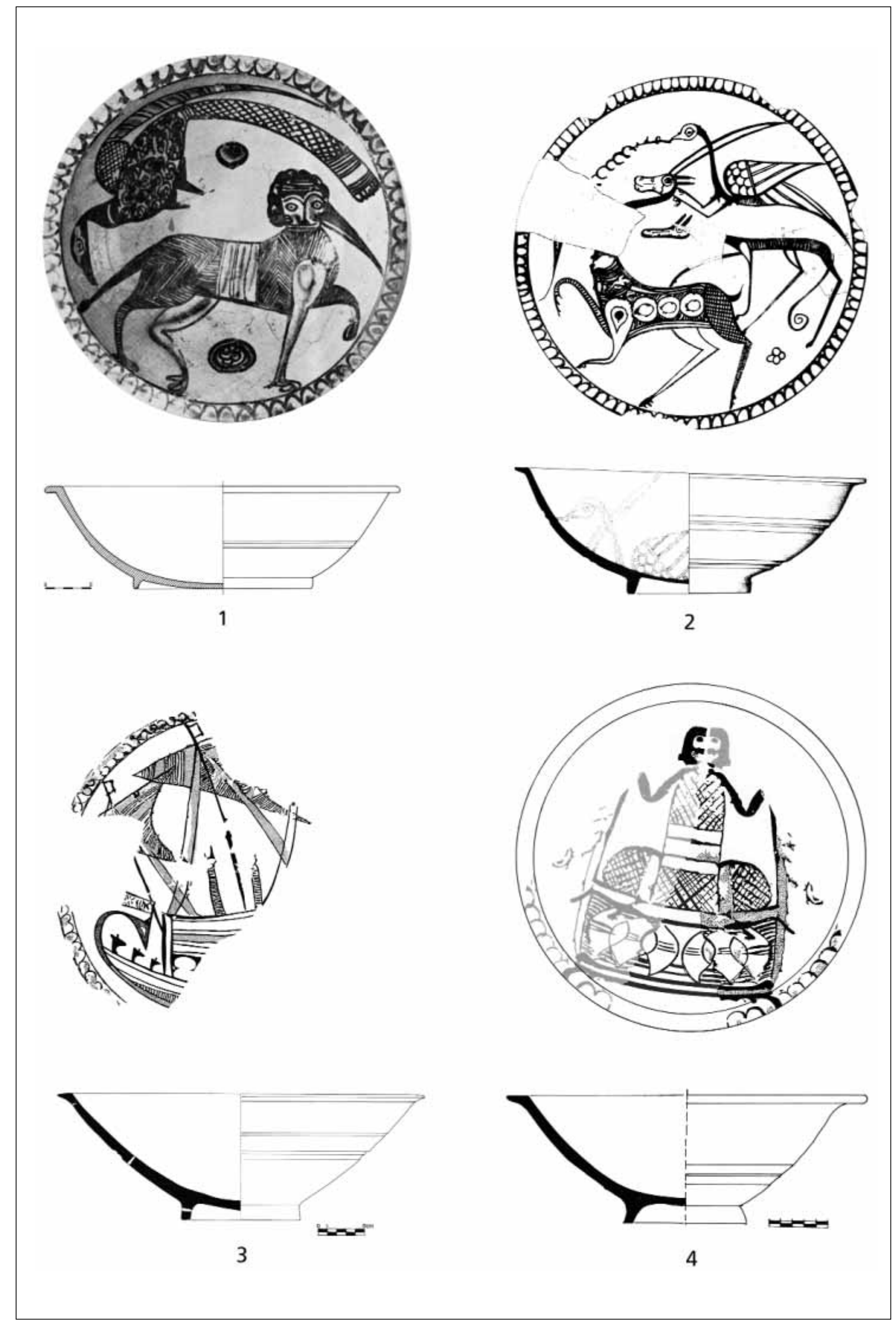

Fig. 9. Serie de producción en "verde y mangeso" de procedencia malagueña o dianense?. I.-San Zeno (Pisa). 2.-Alcazaba de Mértola (Portugal) 3.-Denia 4.-Almudayna (Mallorca). 